Carbon nanofiber nanoelectrodes for neural stimulation and chemical detection:

The era of "smart" deep brain stimulation

Jessica E. Koehne, NASA Ames Research Center, Moffett Field, CA

A sensor platform based on vertically aligned carbon nanofibers (CNFs) has been developed. Their inherent nanometer scale, high conductivity, wide potential window, good biocompatibility and well-defined surface chemistry make them ideal candidates as biosensor electrodes. Here, we report two studies using vertically aligned CNF nanoelectrodes for biomedical applications. CNF arrays are investigated as neural stimulation and neurotransmitter recording electrodes for application in deep brain stimulation (DBS). Polypyrrole coated CNF nanoelectrodes have shown great promise as stimulating electrodes due to their large surface area, low impedance, biocompatibility and capacity for highly localized stimulation. CNFs embedded in $\mathrm{SiO}_{2}$ have been used as sensing electrodes for neurotransmitter detection. Our approach combines a multiplexed CNF electrode chip, developed at NASA Ames Research Center, with the Wireless Instantaneous Neurotransmitter Concentration Sensor (WINCS) system, developed at the Mayo Clinic. Preliminary results indicate that the CNF nanoelectrode arrays are easily integrated with WINCS for neurotransmitter detection in a multiplexed array format. In the future, combining CNF based stimulating and recording electrodes with WINCS may lay the foundation for an implantable "smart" therapeutic system that utilizes neurochemical feedback control while likely resulting in increased DBS application in various neuropsychiatric disorders. In total, our goal is to take advantage of the nanostructure of CNF arrays for biosensing studies requiring ultrahigh sensitivity, high-degree of miniaturization, and selective biofunctionalization.

\title{
Biography
}

Dr. Jessica E. Koehne is a research scientist at the NASA Ames Center for Nanotechnology where she leads the Nano-Biosensors Group. Her research interests include the interface between nanoscale materials, electronics and biological systems with an emphasis on biosensing. Dr. Koehne has developed carbon nanotube and nanofiber based sensor platforms for the detection of DNA, rRNA, proteins and neurotransmitters with applications ranging from point-of-care to homeland security. Dr. Koehne has published over 40 peer reviewed articles in the field of nanotechnology and has received numerous awards for technical achievement including the 2011 Presidential Early Career Award for Scientists and Engineers. 


$$
0
$$




\section{Carbon nanofiber nanoelectrodes for}

\section{neural stimulation and chemical detection \\ The era of "smart" deep brain stimulation}

Jessica E. Koehne

NASA Ames Research Center

Moffett Field, CA 


\section{Outline}

- Biosensing motivation

- Structure and fabrication of carbon nanofibers

- Application of carbon nanofiber electrodes in deep brain stimulation therapy

- Neurochemical recording by carbon nanofiber electrodes and Wireless Instantaneous Neurotransmitter Concentrator Sensor system 


\section{NASA Ames Research Center}

- Established in 1939 as the second laboratory of the National Advisory Committee for Aeronautics (named after NACA chair, Joseph S. Ames)

- Ames is 1 of 10 NASA field centers

- Located in the heart of the silicon valley

- High-tech companies, start-ups, biotechnology

- Some of Ames Technical Areas

- Astrobiology

- Thermal protective systems

- Simulation technology

- Atmospheric science

- Fundamental space biology

- Human factors research

- Nanotechnology

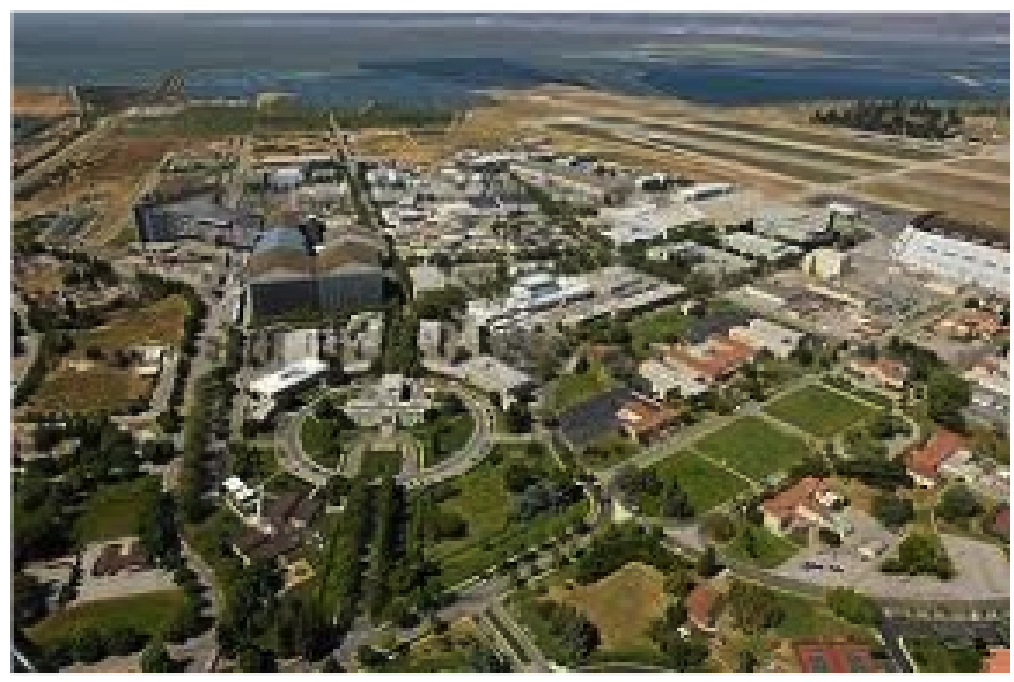




\section{Biosensor Motivation}

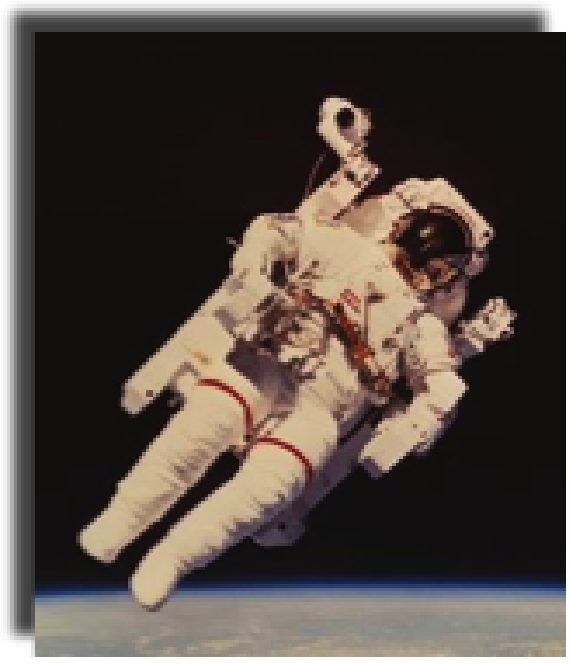

Outside Applications and Customers

- Medical Diagnostics

- NIH, DARPA

- Environmental Monitoring

- EPA, NIH

- Biowarfare agent detection

- DHS, DARPA

- Food Safety

- FDA
NASA Applications

- Astronaut health monitoring

- Lab-on-a-chip

- Water Quality monitoring

- Pathogen detection on ISS and long duration missions

- Planetary exploration

- Life on other planets

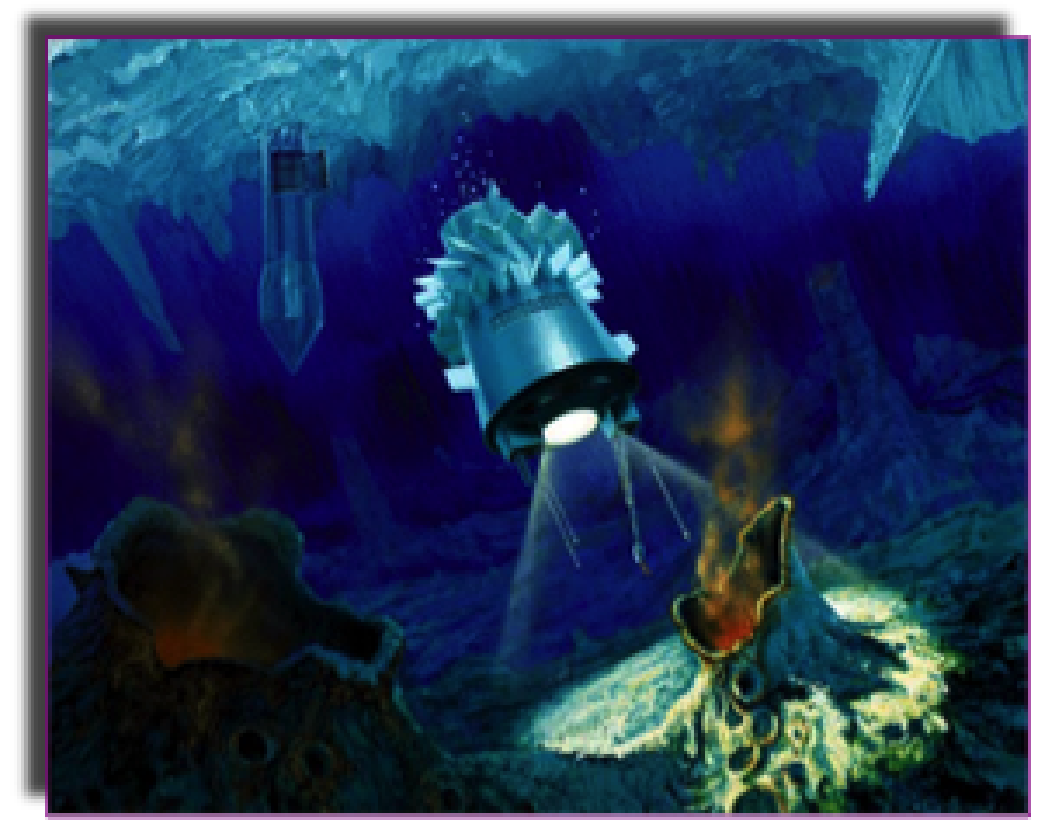




\section{What are Carbon Nanofibers (CNFs)?}

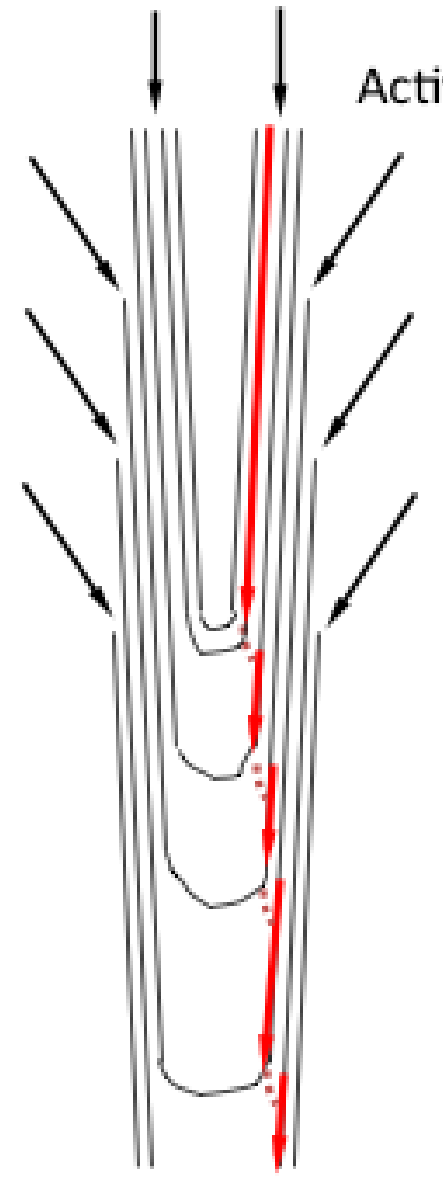

Bamboo-like CNFs

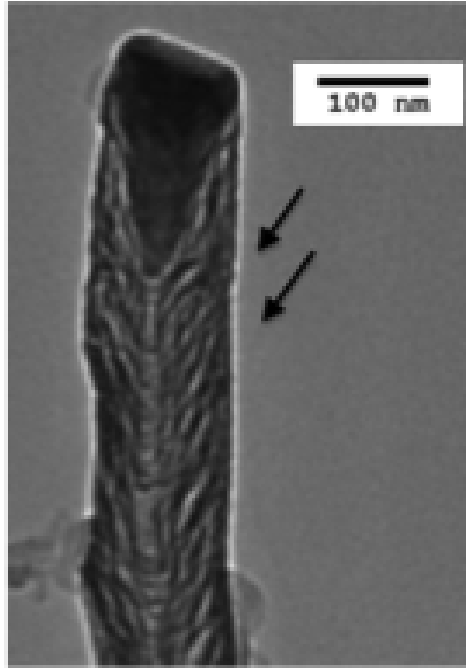

TEM of CNF

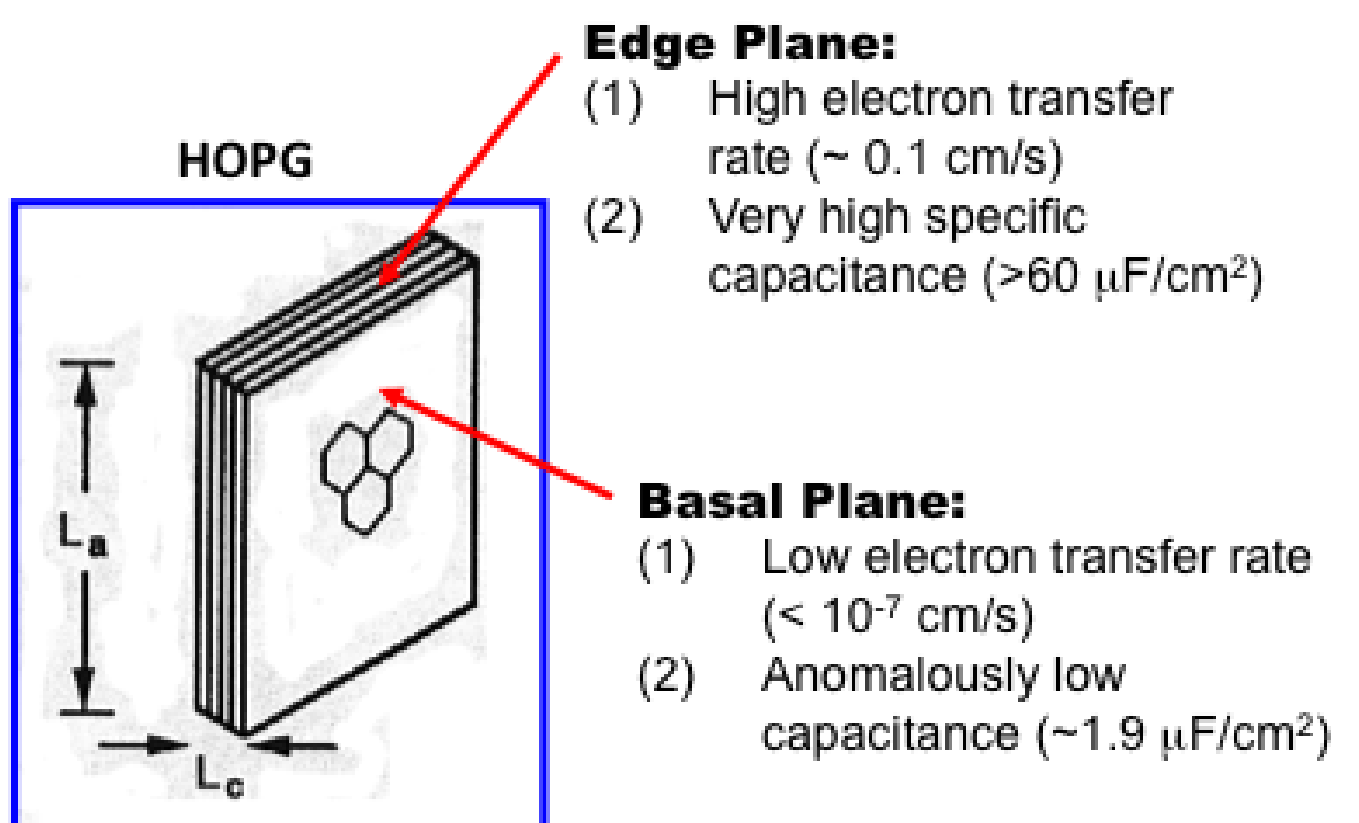

R. L. McCreery, A. J. Bard, in Electroanalytical Chemistry, Ed., 1991, 17, 221.

\section{Why CNF as biosensor electrode material?}

1) Good conductivity

2) Wide potential window

3) Many active sites for electron transfer

4) Easy to pattern, grow and process on silicon devices 


\section{CNF Growth by Plasma Enhanced Chemical Vapor Deposition (PECVD)}

PECVD Reactor Schematic

Pumping Outlet Pressure Gauge RGA

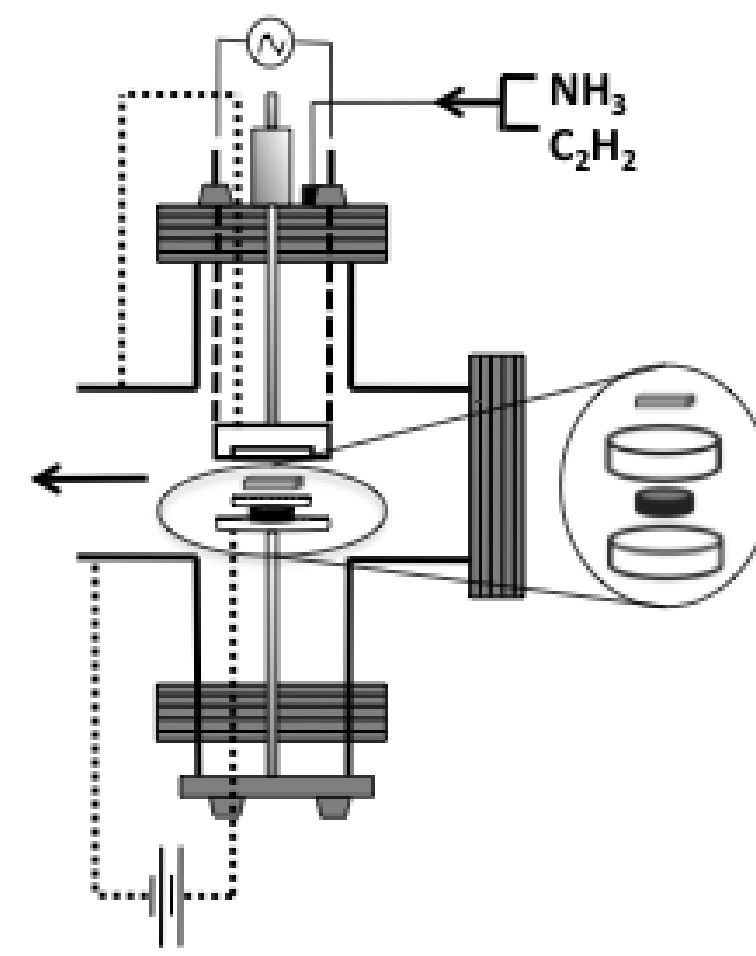

Sample

Ta Foil

Graphite Spacer

Stainless Steel Electrode
Custom Built PECVD Reactor

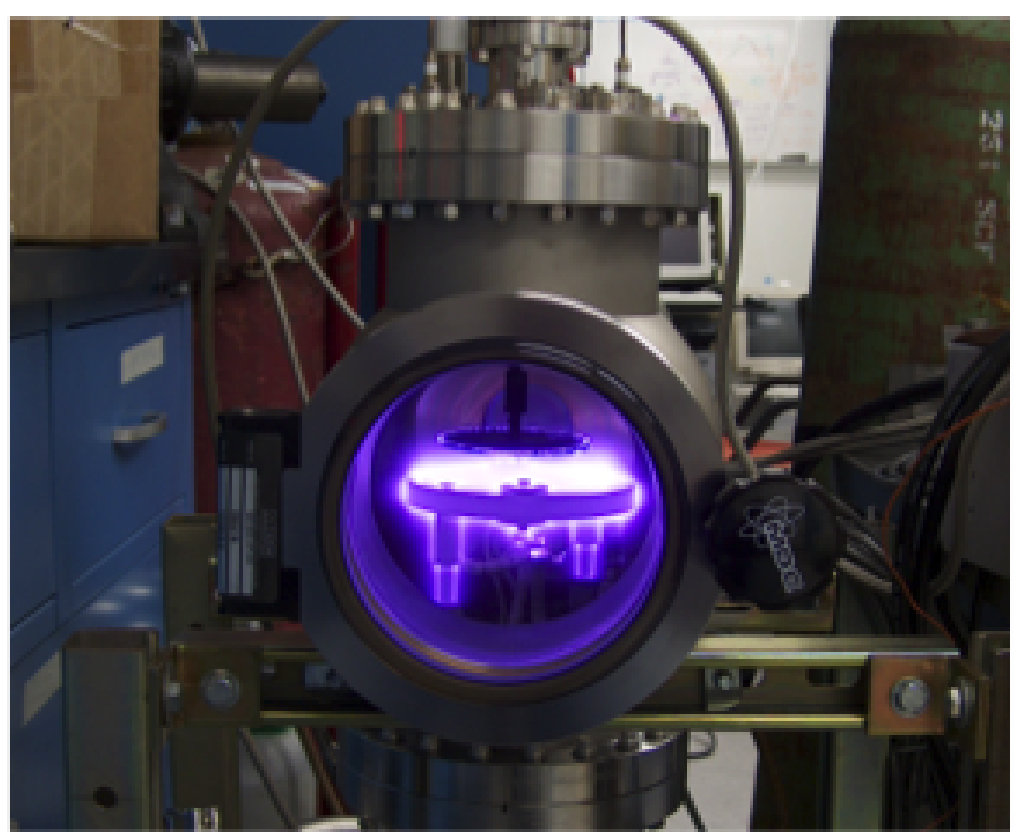

Growth Process

- Heated to $650 \mathrm{C}$

- Plasma discharge $500 \mathrm{~W}, 530 \mathrm{~V}, 0.97 \mathrm{~A}$

- $150 \mathrm{sccm} \mathrm{NH} \mathrm{NH}_{3} / 50 \mathrm{sccm} \mathrm{C}{ }_{2} \mathrm{H}_{2}, 5-6$ torr

- Growth rate- $1000 \mathrm{~nm} / \mathrm{min}$

- Quality is good, alignment is good 


\section{Define CNF Placement by \\ Catalyst Placement}

As Grown CNFs

Continuous Layer of Catalyst

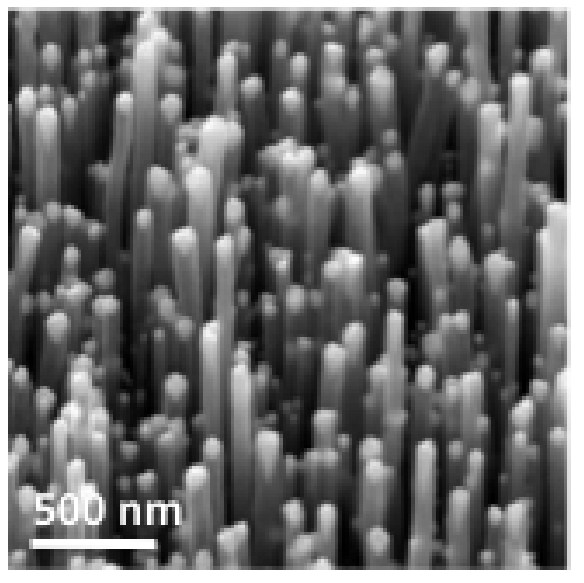

$\mathrm{SiO}_{2}$ Encapsulated CNFs
Photolithography Defined Catalyst Spots
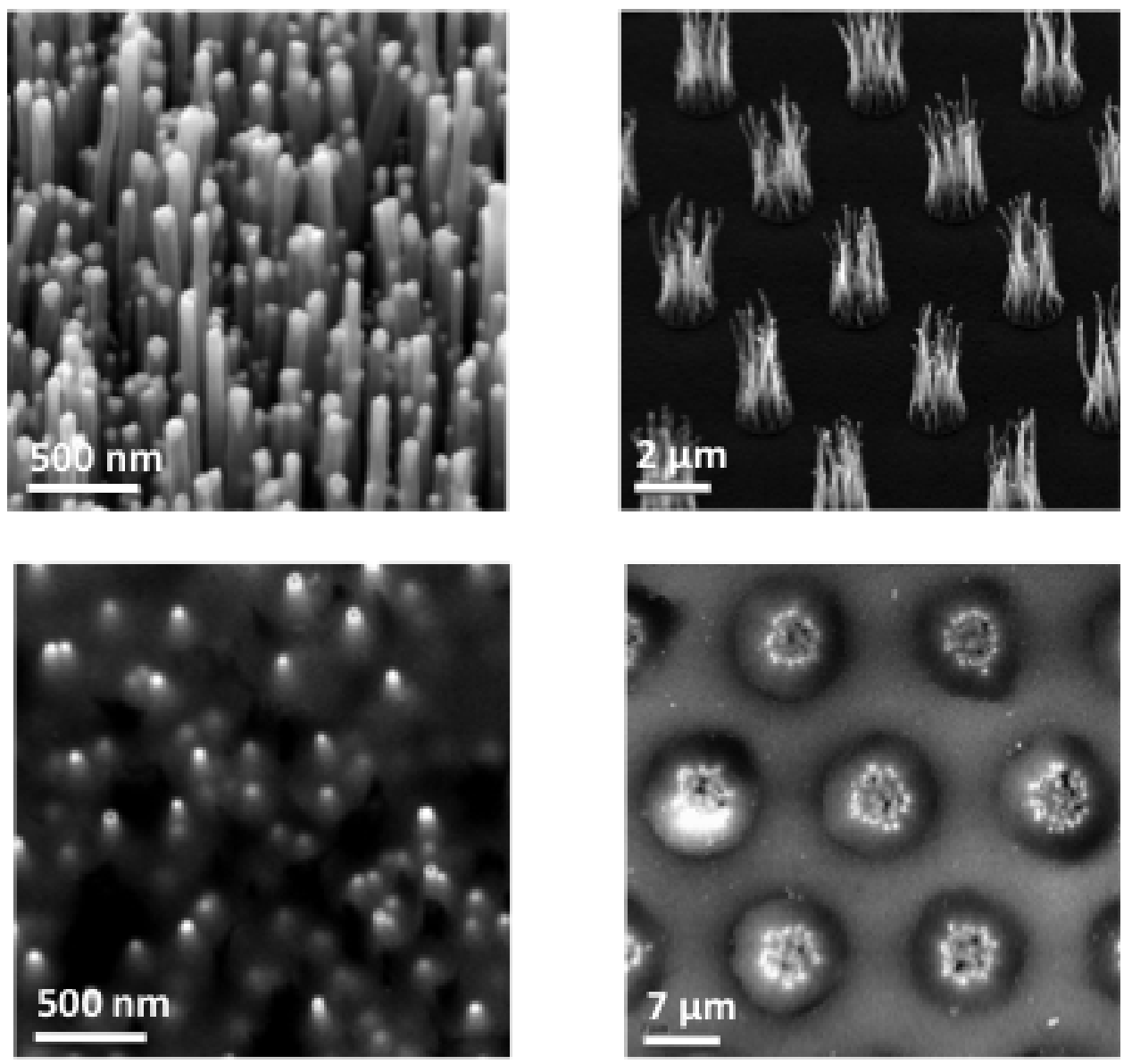

Electron Beam Lithography Defined Catalyst Spots
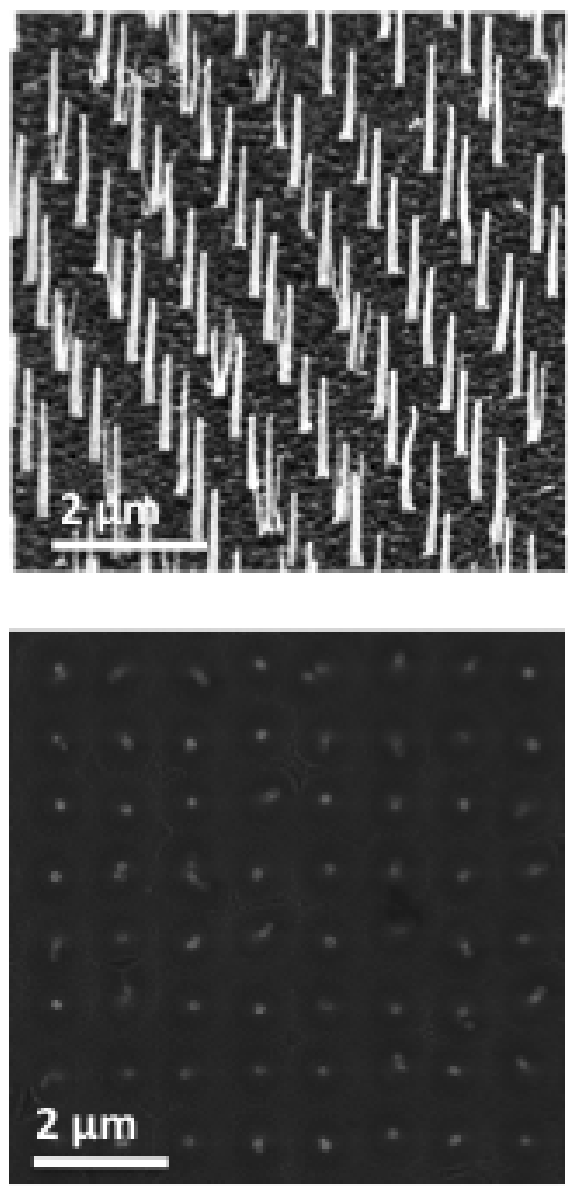


\section{Fabrication of $3 \times 3$ Array}
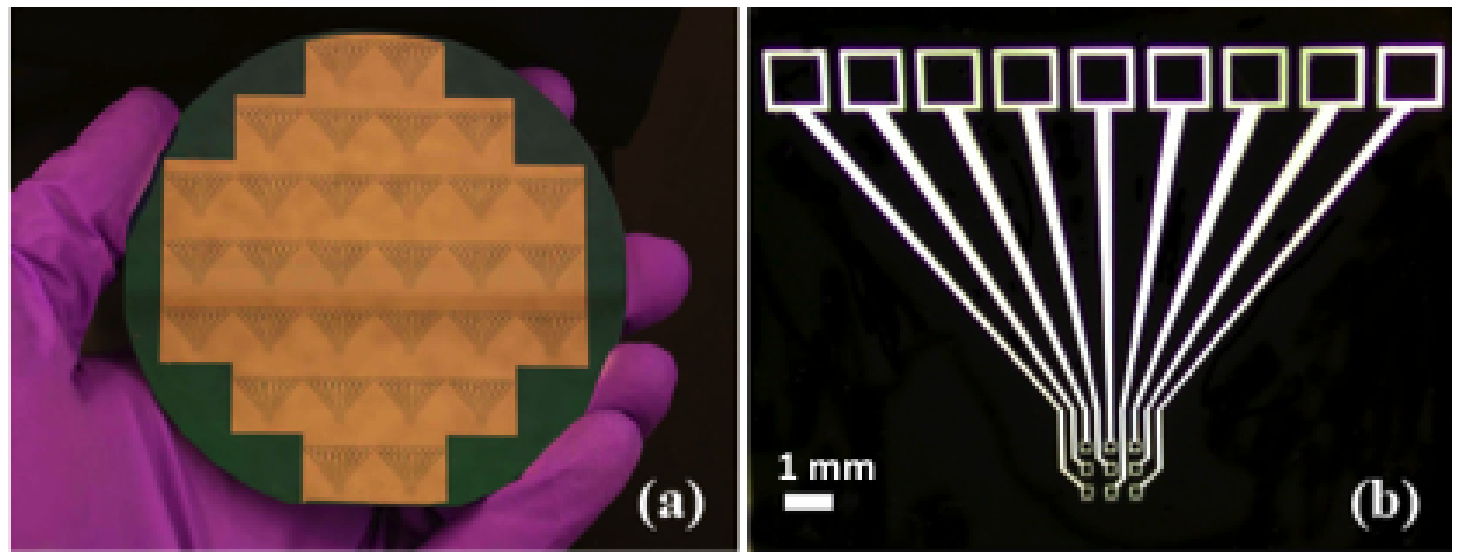

30 devices on a 4" Si wafer
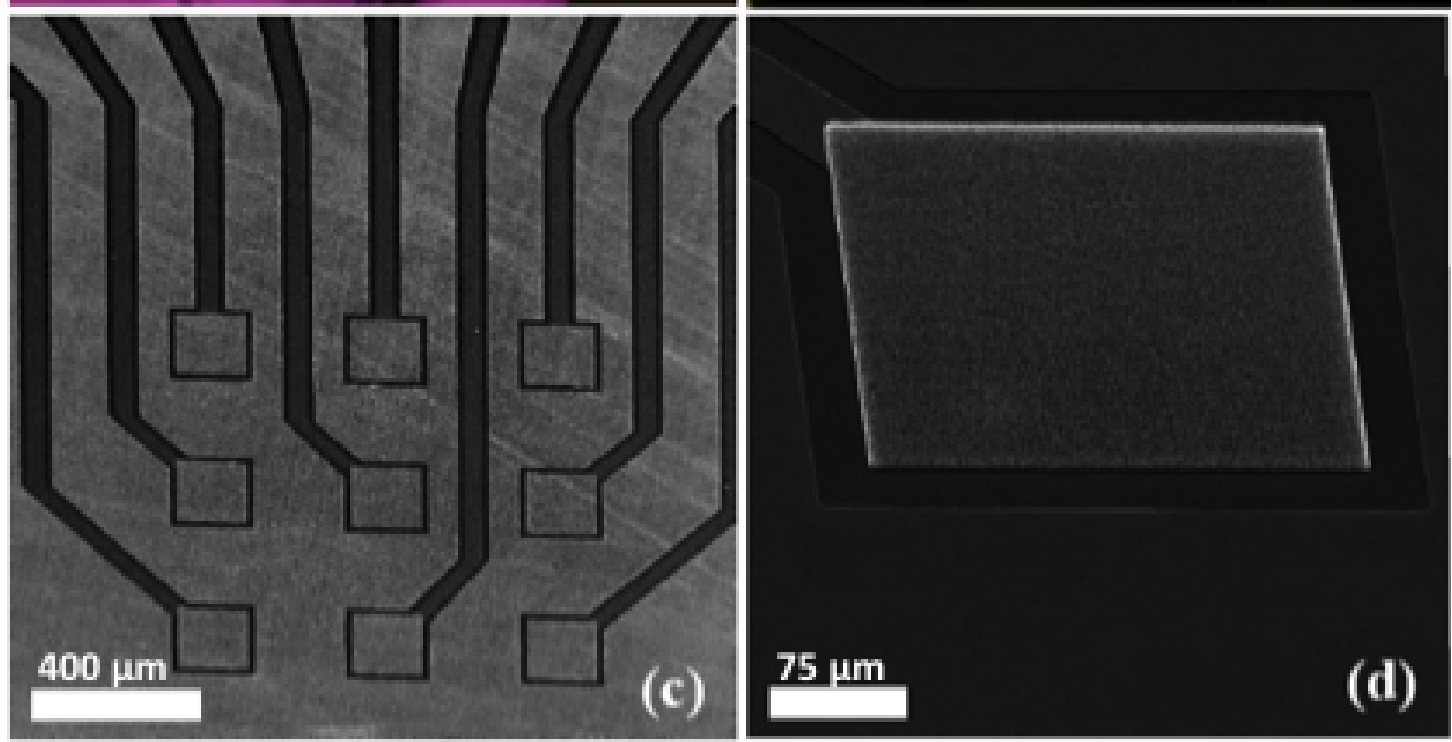

- $200 \mu \mathrm{m}$ by $200 \mu \mathrm{m}$ electrode dimensions

- 9 individually addressed electrodes

- potentially 9 different target molecules 


\section{Deep Brain Stimulation}

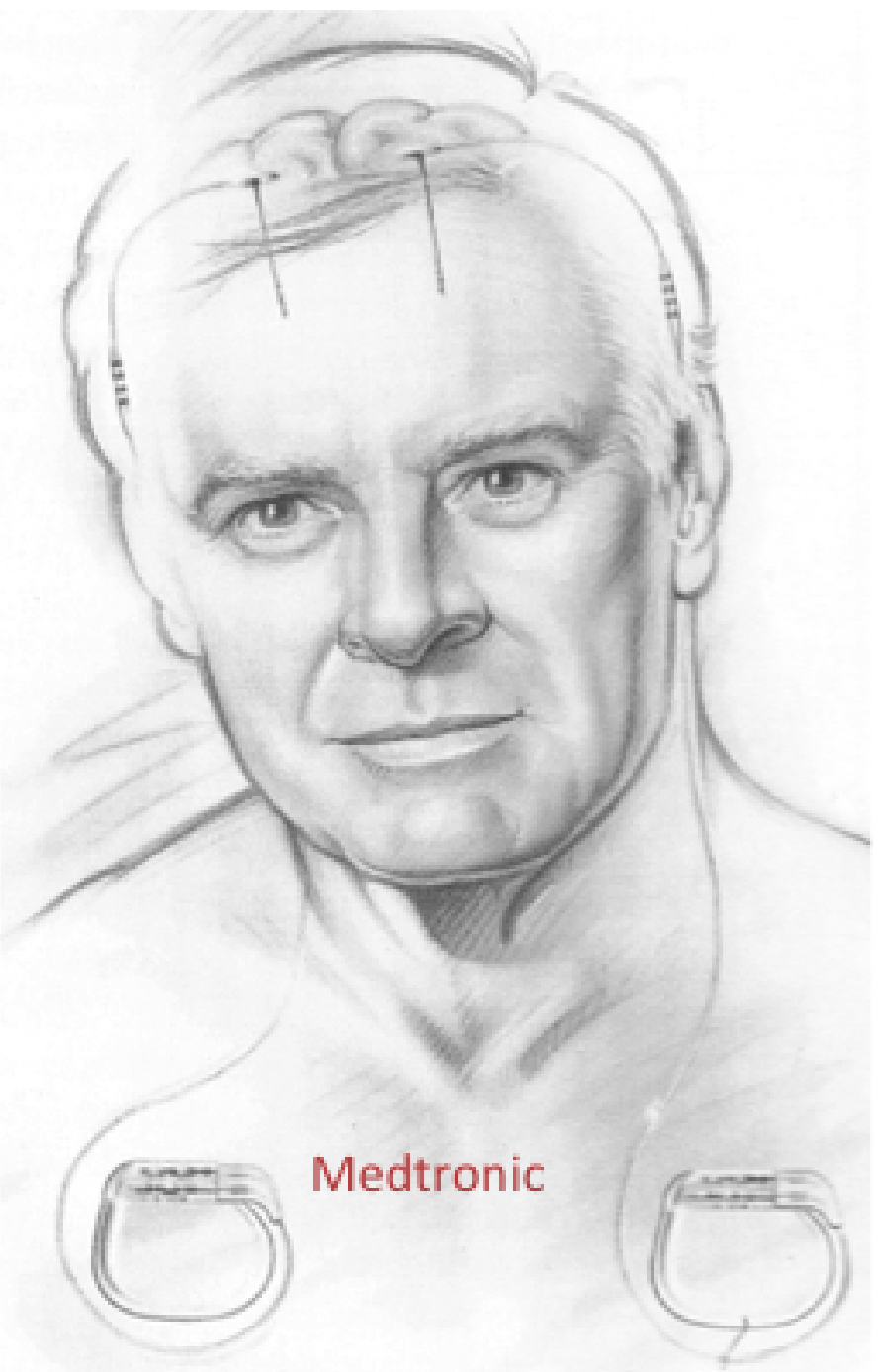

Deep Brain Stimulation (DBS)

-Started in the 1960's

-Over 80,000 successful surgeries

-Has been demonstrated to be an effective neurosurgical treatment for several pathologies including:

- tremor

- epilepsy

- Parkinson's disease

- depression

- Tourette syndrome

- chronic pain

How DBS Works

- Brain pacemaker, electrical impulses to different areas of the brain

-Stimulation 24/7

\section{Potential Improvements}

-Time consuming and difficult to program without feedback -Want real-time monitoring of the neurochemical output -Development of chemically-guided placement of DBS electrodes in vivo.

Clinical efficacy is not questioned, but mechanisms are very poorly understood 


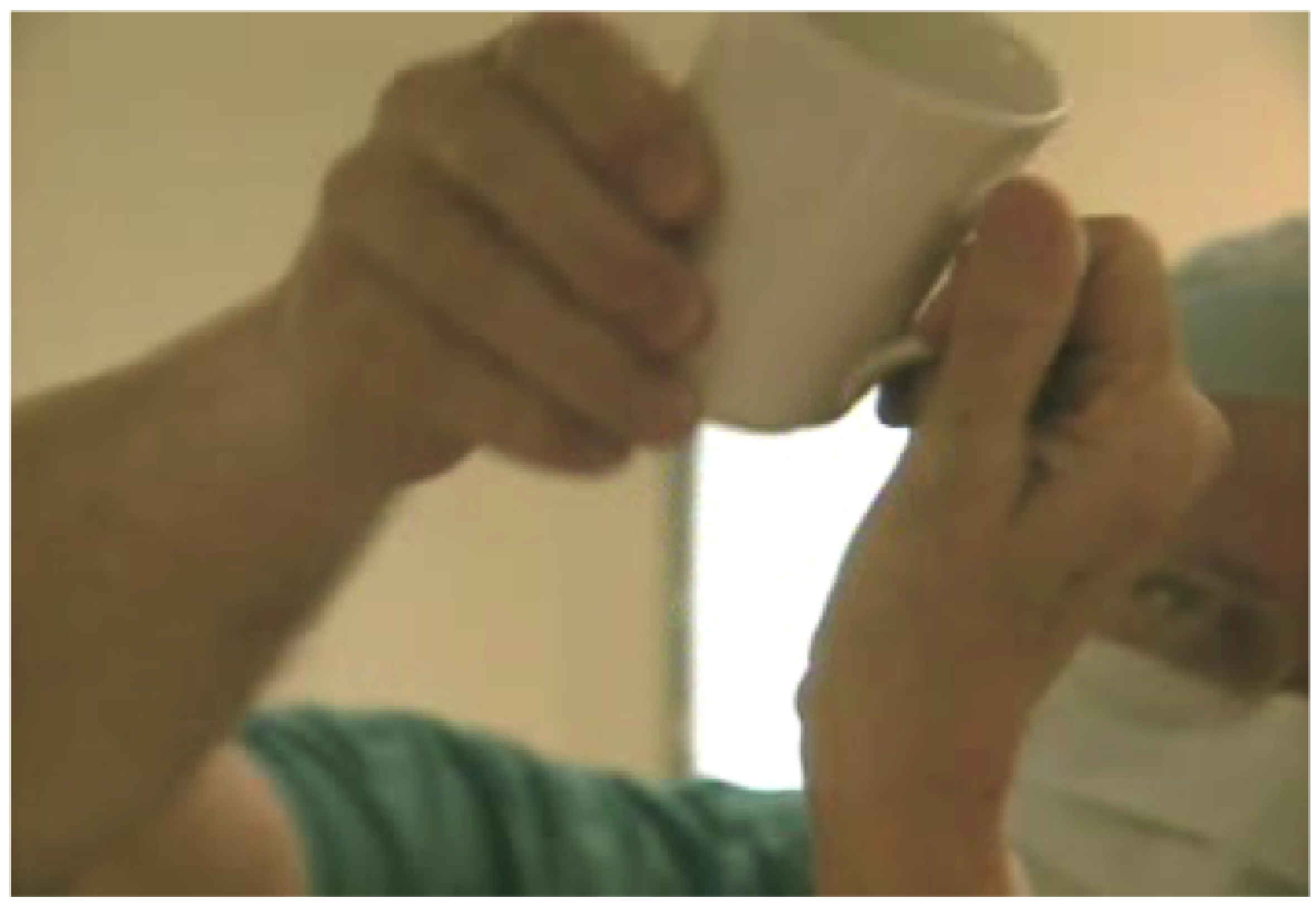

http://professional.medtronic.com/therapies/deep-brain-stimulation/presentations-and-downloads/index.htm 


\section{History of DBS}

- DBS used for pain control since 1960s

- DBS for tremor began in Europe (1987)

- Europe: CE mark approval for

- Activa Tremor Control Therapy in 1993

- Activa Parkinson's Control Therapy in 1998

- USA: FDA approval for

- Activa ${ }^{\circ}$ Tremor Control Therapy in 1997

- Activa Parkinson's Control Therapy in 2002 


\section{Deep Brain Stimulation Electrodes}

DBS Electrodes from Medtronic

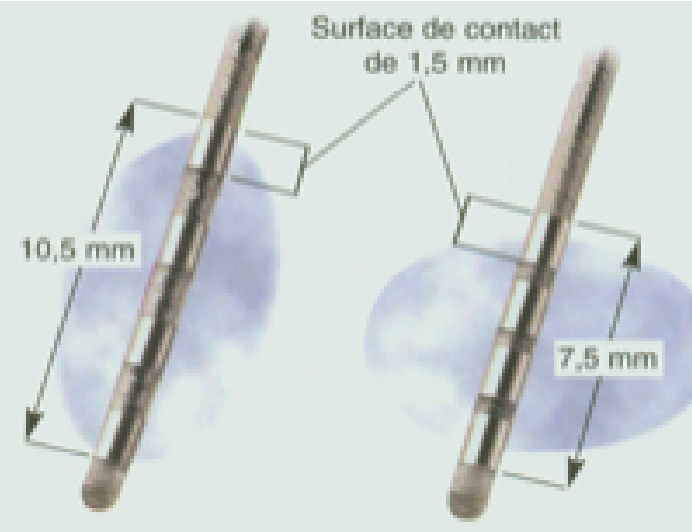

Electrode modele

$$
3387
$$

4 plots de $1,5 \mathrm{~mm}$

espacés de $1,5 \mathrm{~mm}$
Electrode modèle

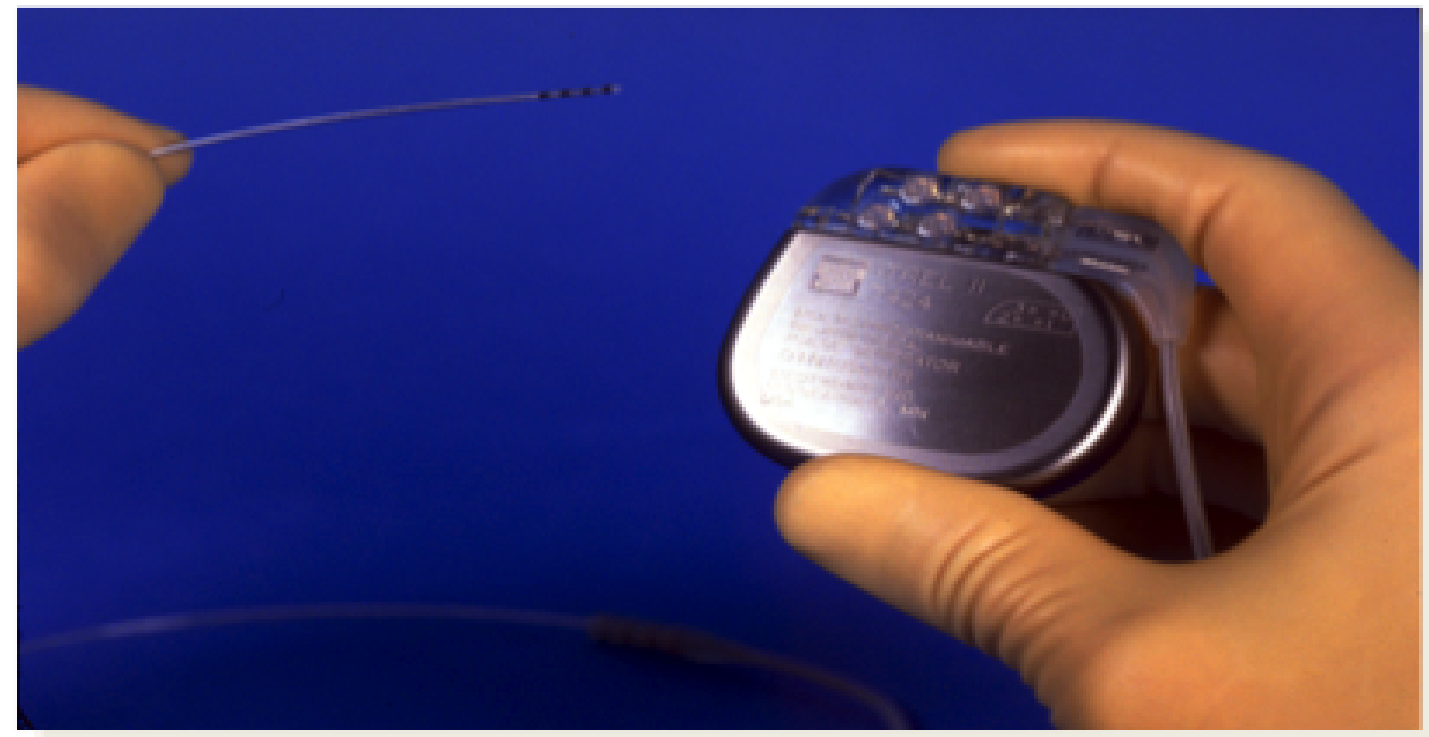

CNF Electrodes
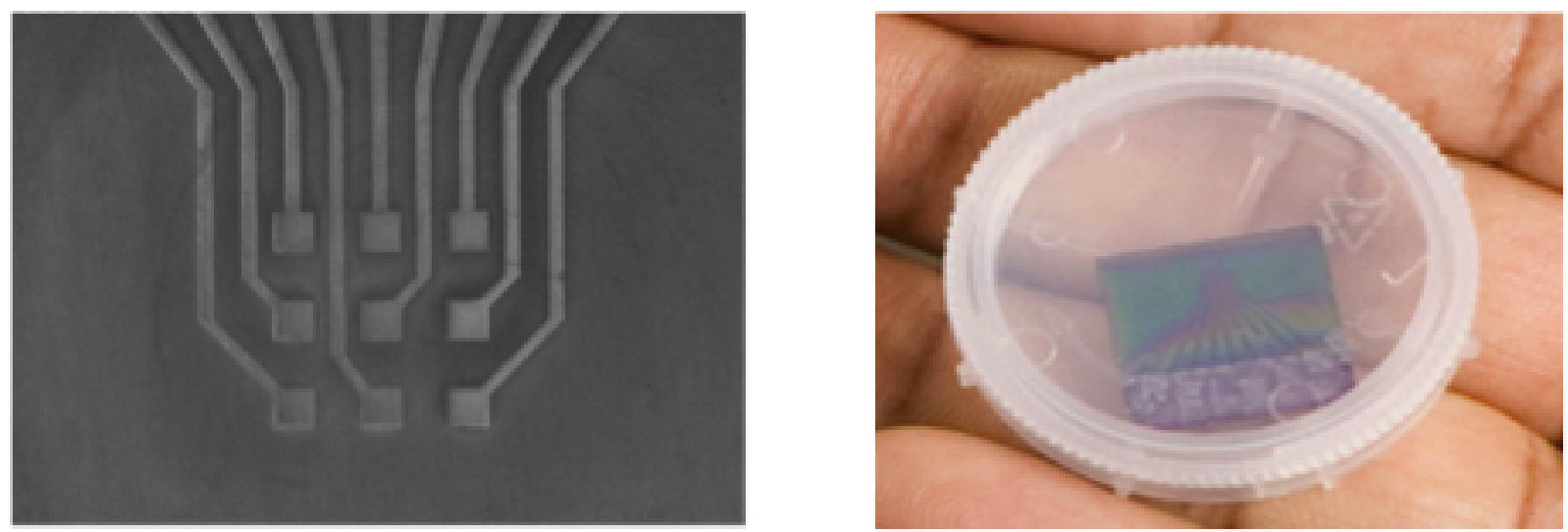

Current $3 \times 3$ CNF device does not have an optimal geometry for implantation but can be used to preliminary in vitro investigations. 


\section{CNF Array for Applications in Deep Brain Stimulation}

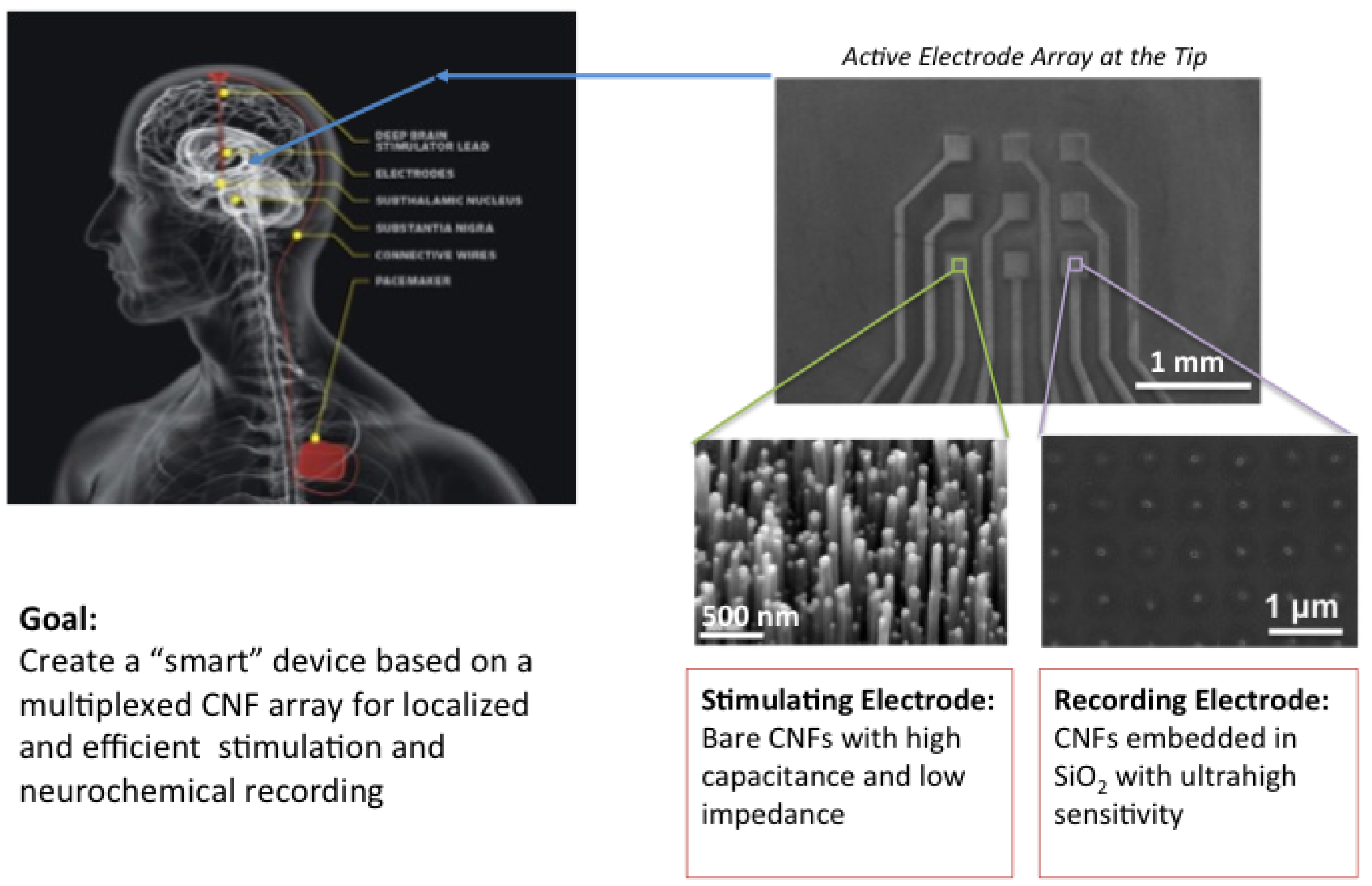




\section{Neural Stimulation Using CNF Array}

\section{Low Impedance}

At $1 \mathrm{kHz}$, the impedance is negligible compared to the solution resistance

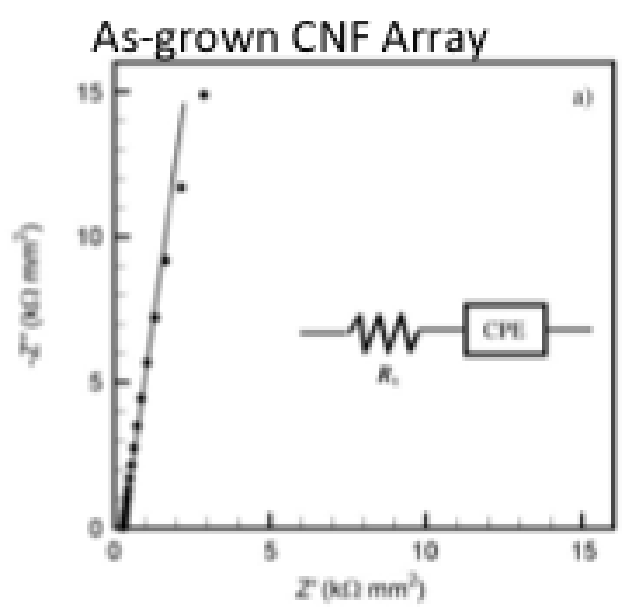

After PPy coating

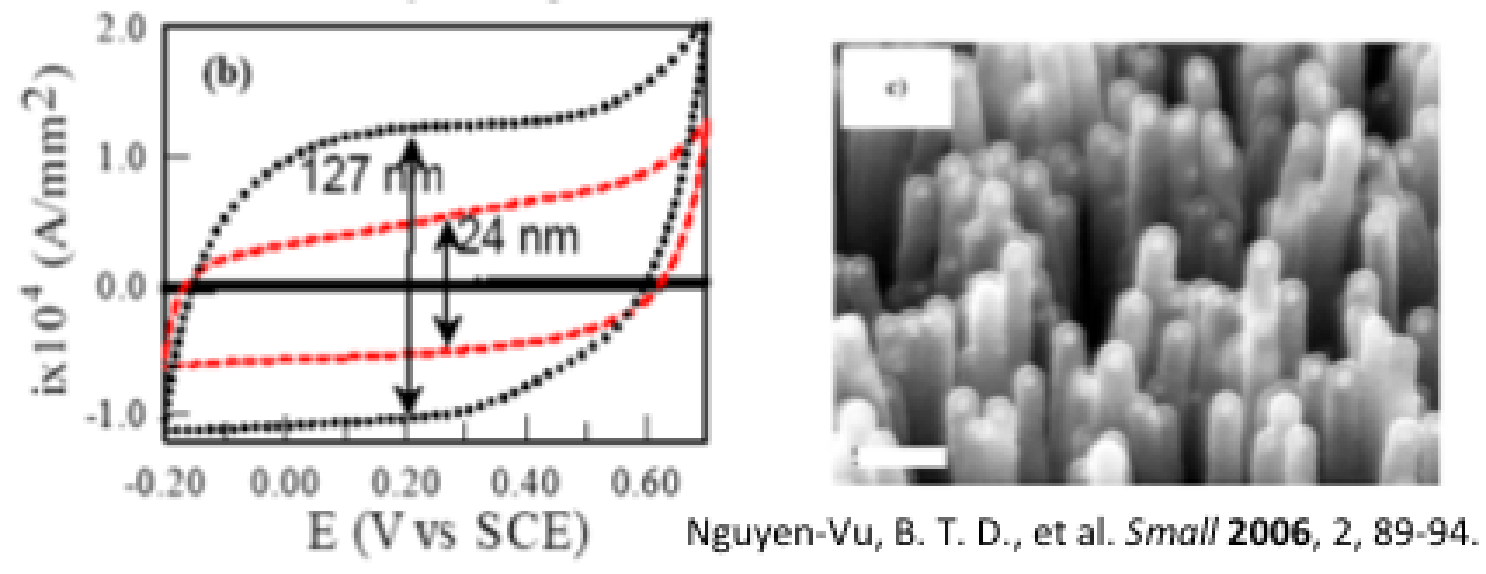

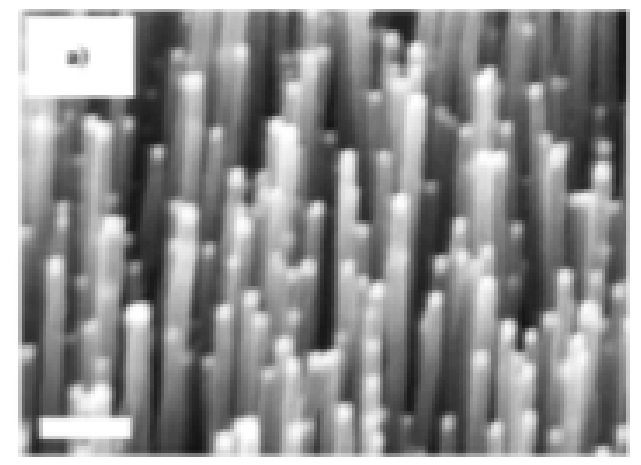

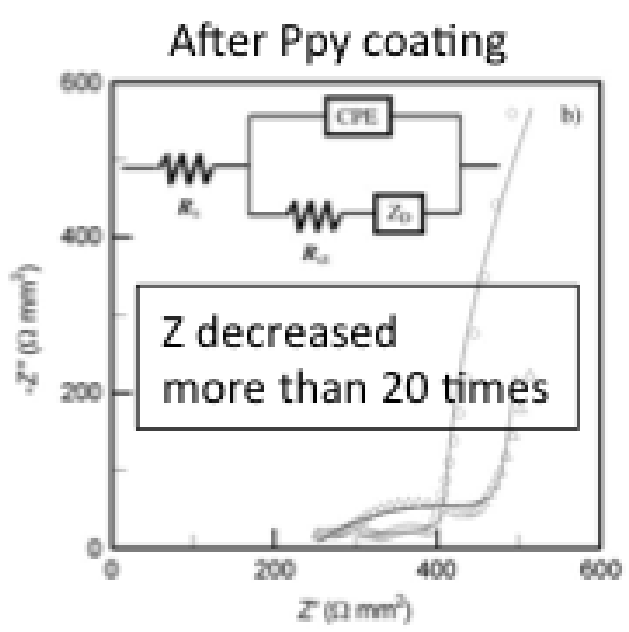




\section{Biocompatibility}

\section{Optimization though chemical modification}

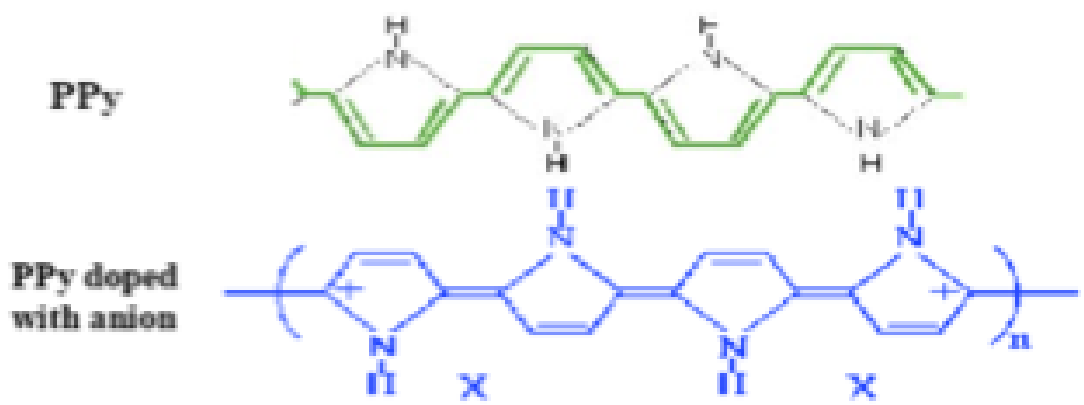

Freedom for modification:

(1) Changing anion dopants such as $\mathrm{Cl}^{-}, \mathrm{ClO}_{4}^{-}$, poly(styrenesulfonate) (PSS), other polyelectrolytes, etc.

(2) Loading with drugs such as antibiotics, antiinflammatory molecules, etc. and biomolecules

PPy

functionalized w/ side groups

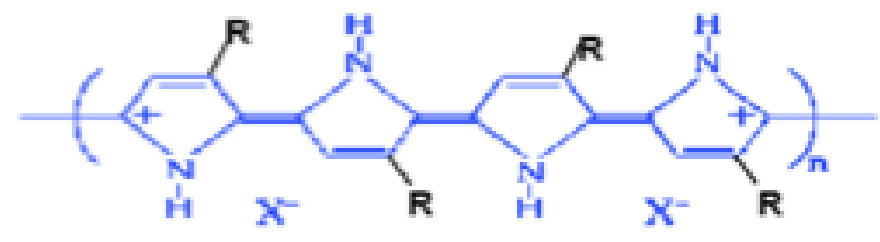
such as nerve growth factors.

(3) Surface functionalization with cell adhesion molecules and specific ligands.
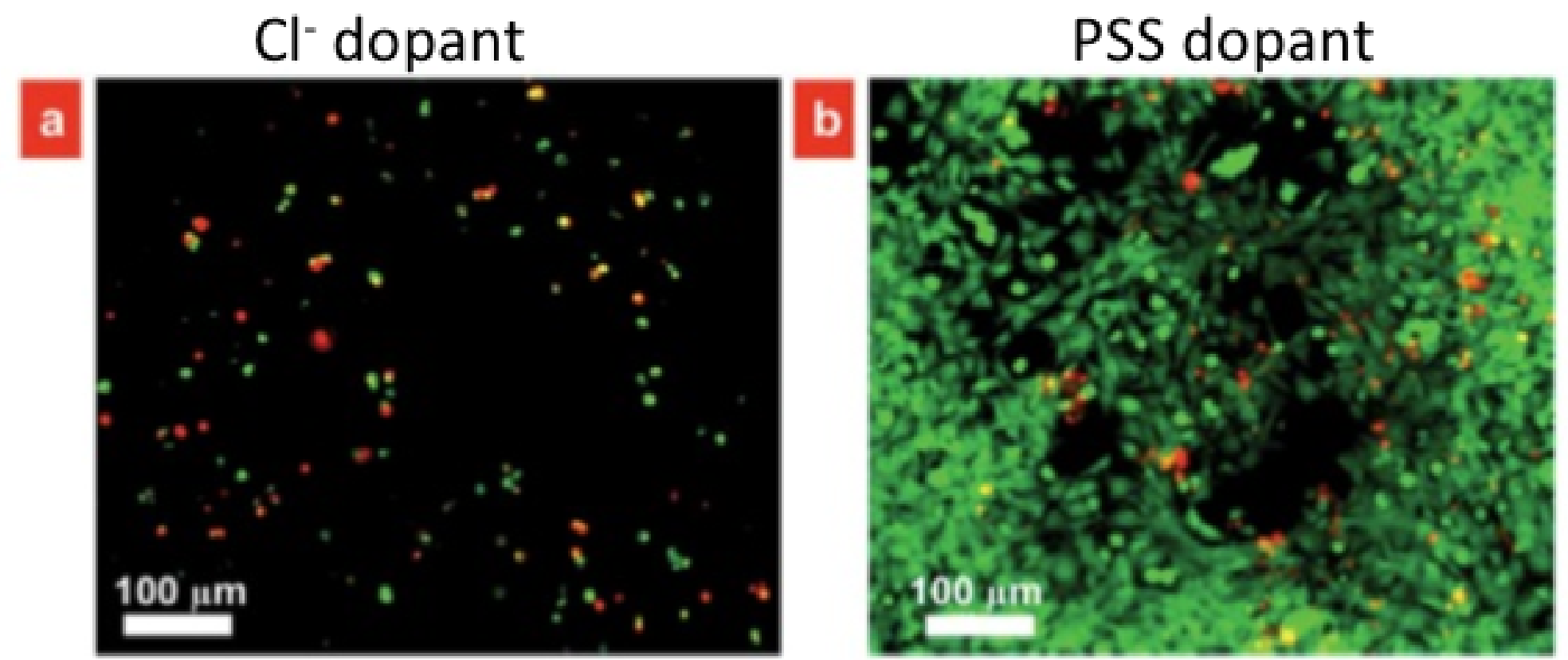

Nguyen-Vu, B. T. D., et al. IEEE Trans. Biomed. Eng. 2007, 54, 1121-1128. 


\section{PC12 cells on PPy coated CNFs}

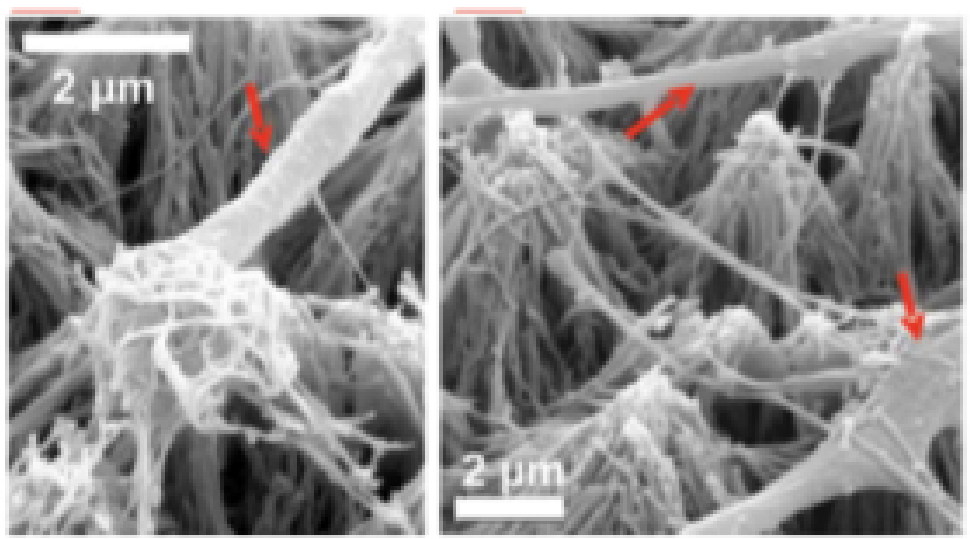

\section{Collapsed CNFs}
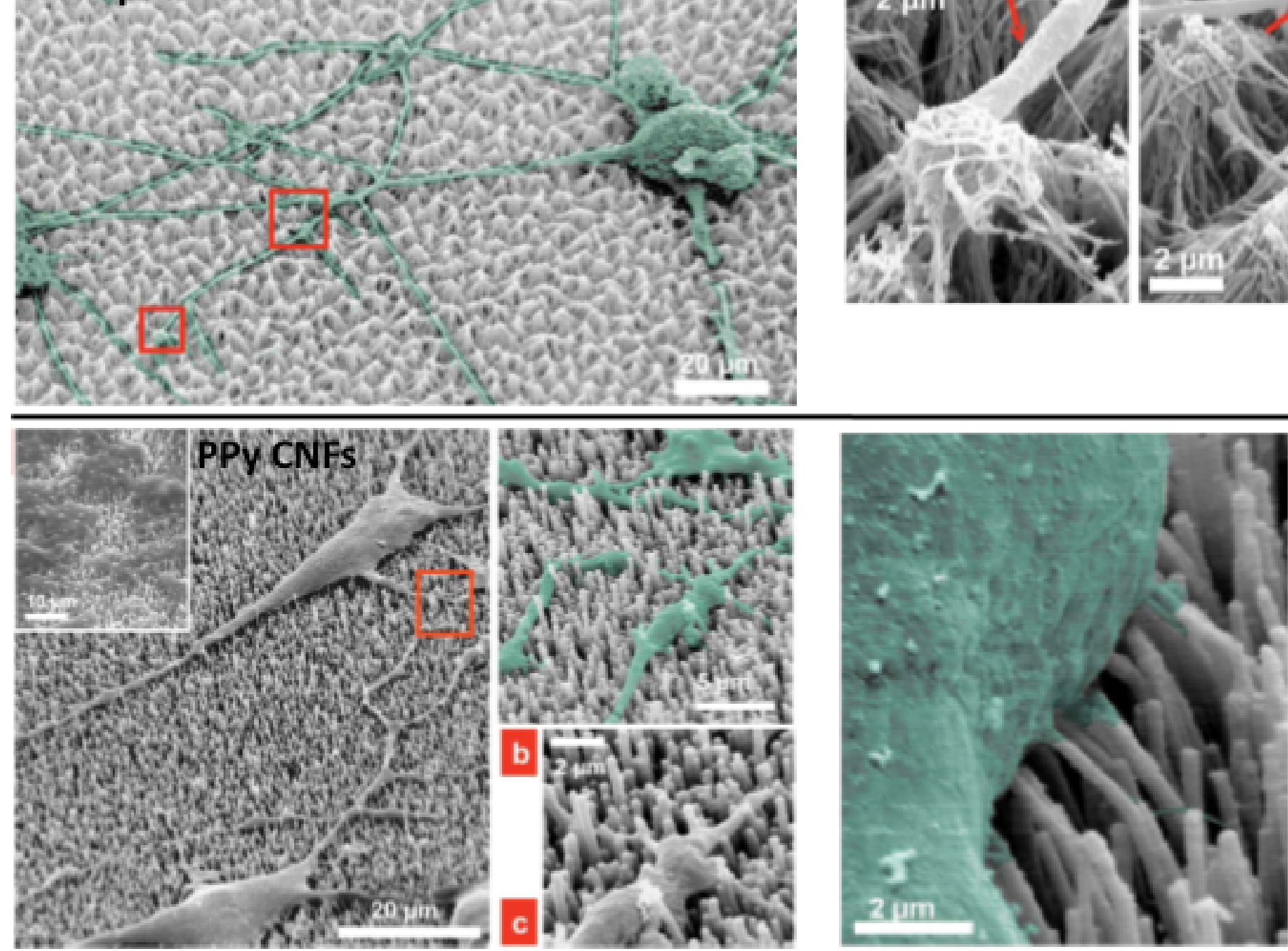

Nguyen-Vu, B. T. D., et al. IEEE Trans. Biomed. Eng. 2007, 54, $1121-1128$. 


\section{Stimulation of Rat \\ Hippocampal Brain Slices}

Ames Research Center

Experiment: Measure voltage for a given stimulation current

Stimulation by:

-W wire

- Pt Microelectrode

- CNFs

- PPy coated CNFs

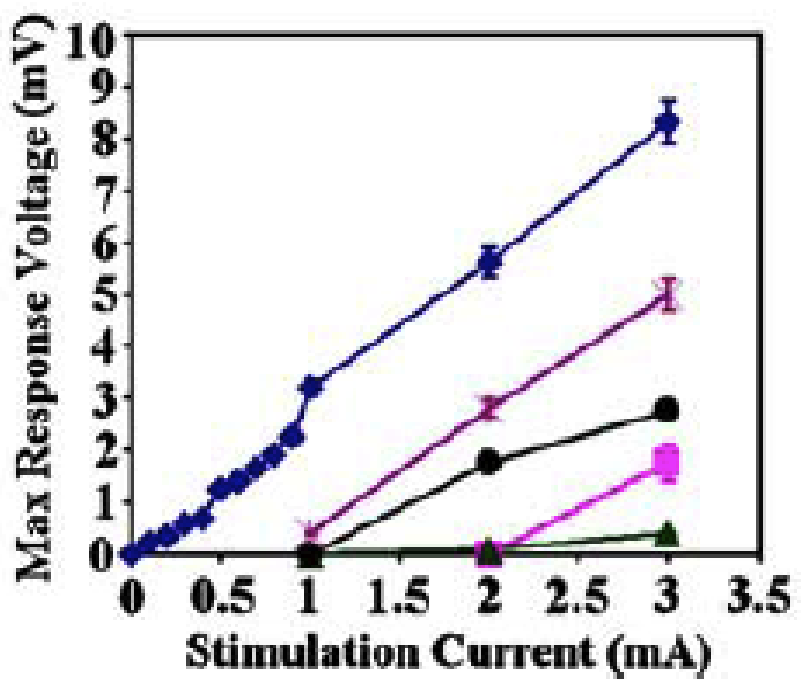

(a) Iungsten Electrode Stimulation (b) Slice Placement on Electrode Array
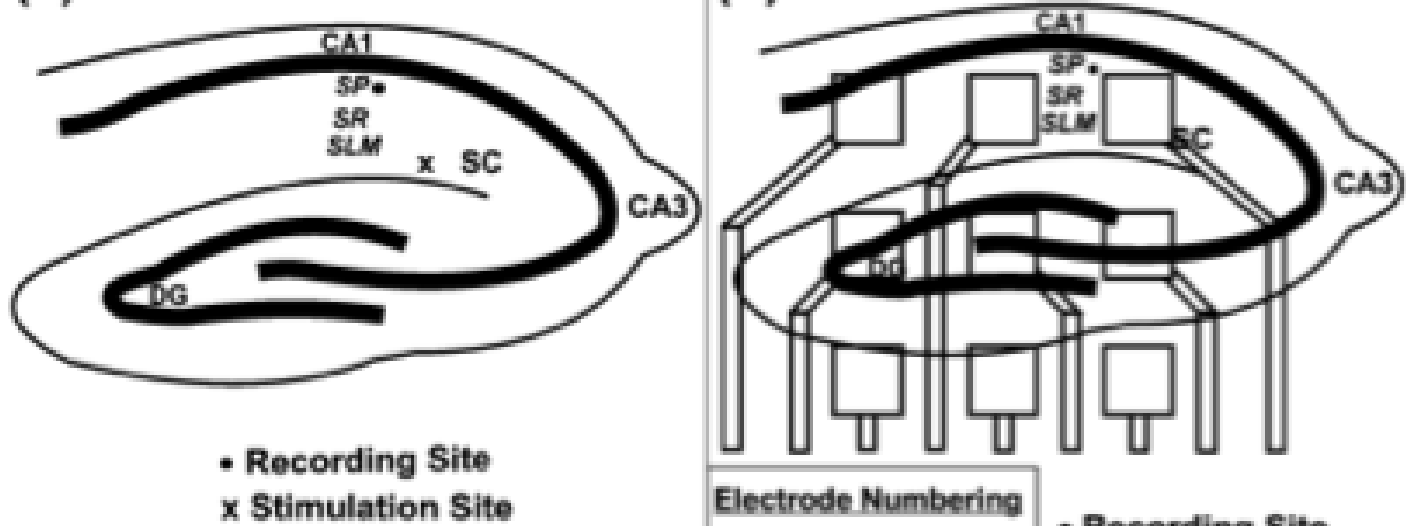

Electrode Numbering

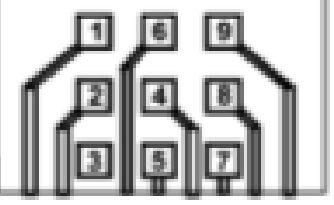

- Recording Site

Stimulus Appliod

between

Electrodes 8 and 9

1) Only PPy coated CNFs were able to stimulate tissue under $1 \mathrm{~mA}$ stimulation current.

2) Only PPy coated CNFs did not induce the electrolysis of water (less than $1 \mathrm{~mA}$ and $1 \mathrm{~V}$ )

de Asis, E. D., et al. Biomed. Microdevices 2009, 11, 801-808. 


\section{Electrochemical Detection of Neurotransmitters}

- Molecules of Interest

- Dopamine

- Movement disorders, addiction

- Serotonin

- Depression, hunger

- Adenosine

- Oxygen

- Hydrogen lons $(\mathrm{pH})$

- Techniques

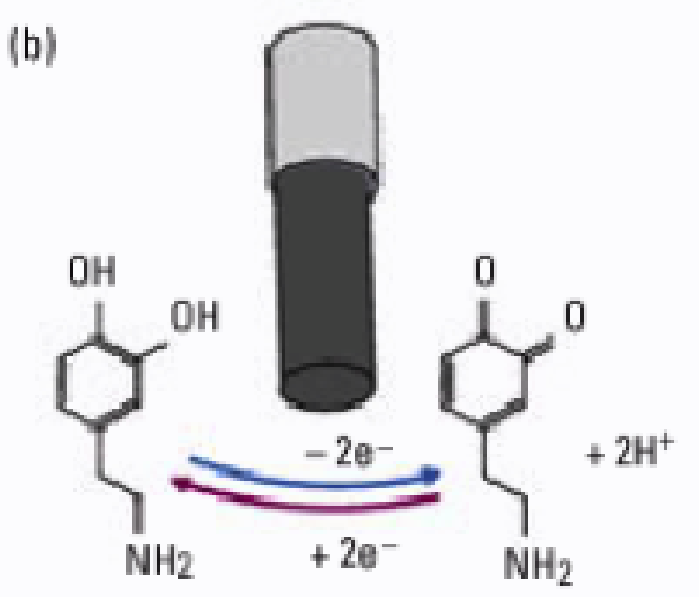

- Differential Pulse Voltammetry

- Fast Scan Cyclic Voltammetry

- Better temporal resolution 


\section{Simultaneous Detection of Neurotransmitters}

Glassy Carbon Electrode

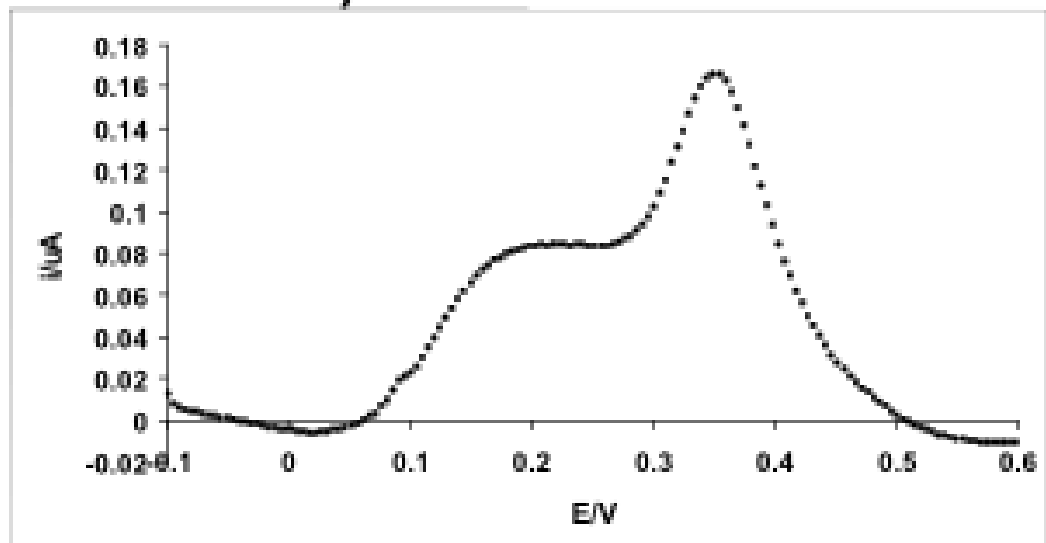

-CNF electrode has ability to distinguish multiple electroactive brain chemicals in a mixture! -Detection limits 50nM for DA and 100nM for 5-HT

\section{Carbon Nanofiber Electrode}
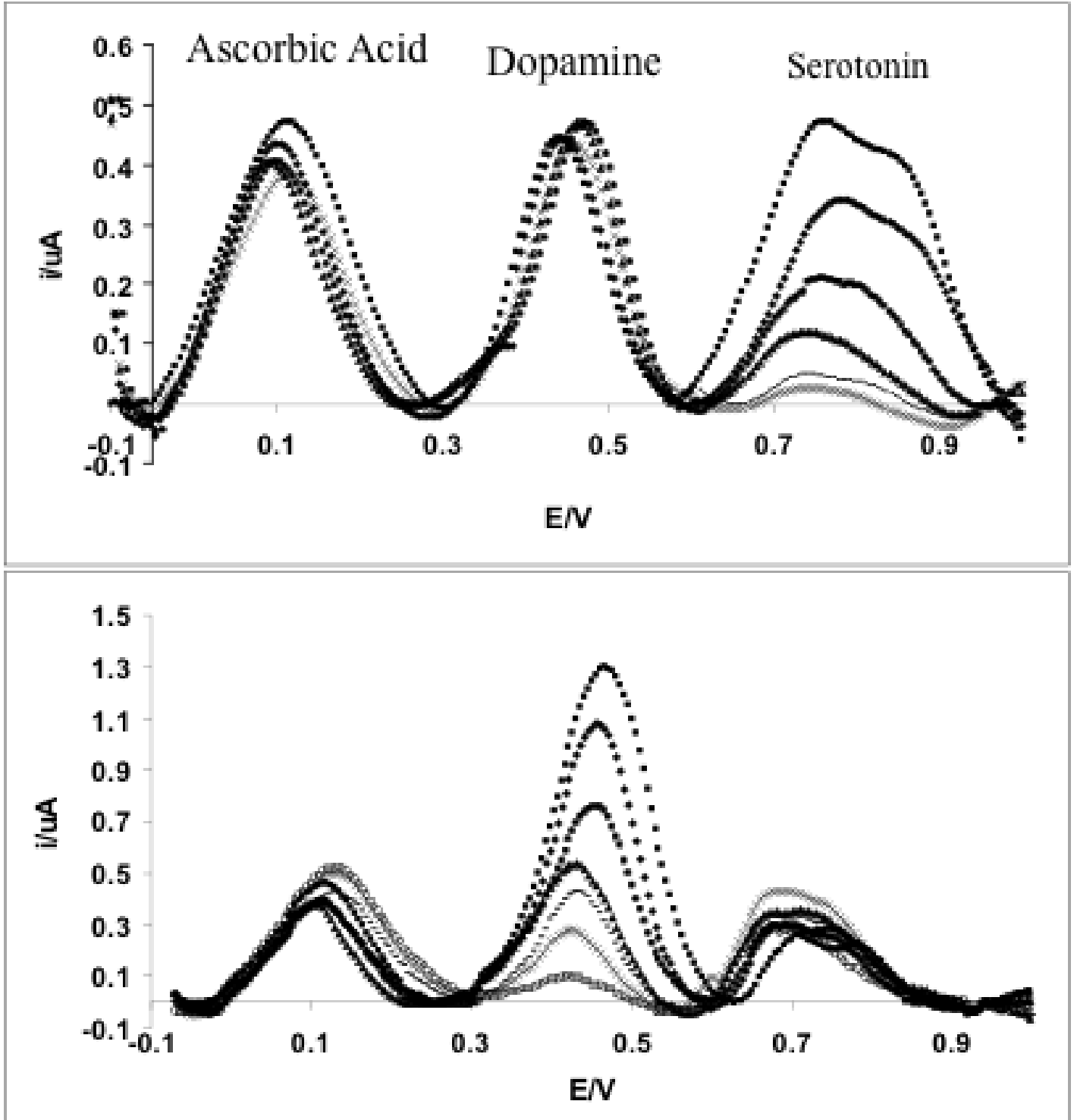
The Mayo Clinic-developed WINCS is a microprocessor-controlled, MRI-compatible, battery-powered instrument that combines Bluetooth $^{\oplus}$ digital telemetry with fast scan cyclic voltammetry and constant potential amperometry.

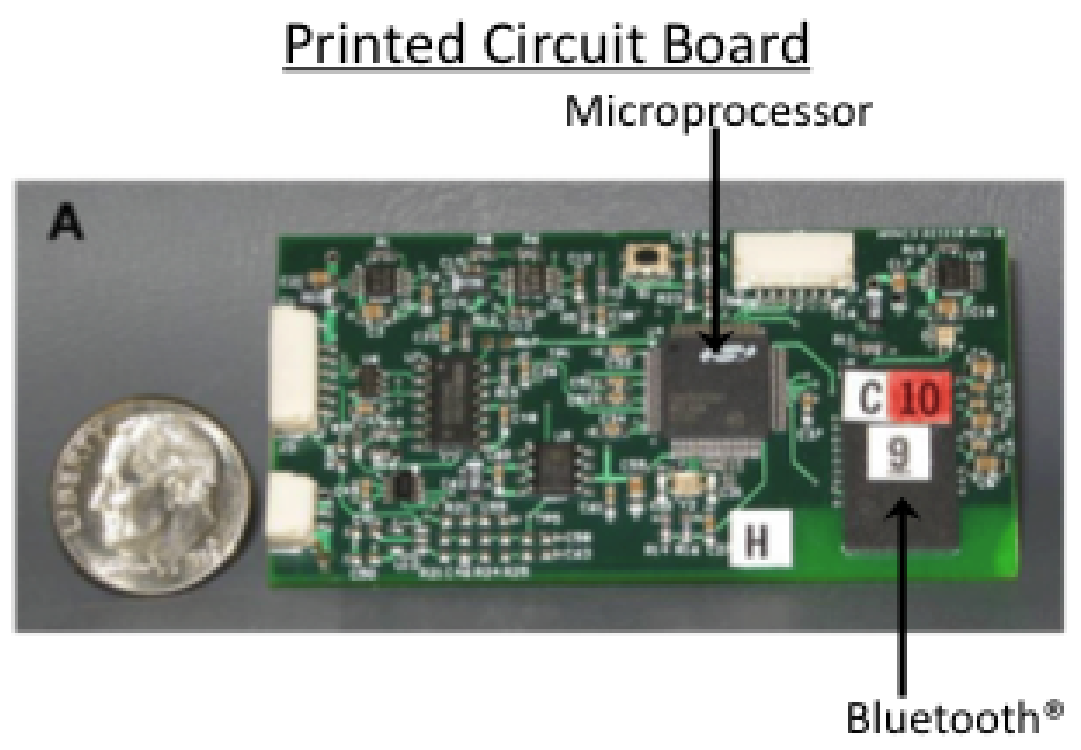

WINCS was designed in compliance with FDA-recognized standards for medical electrical device safety.
Standard Potentiostat

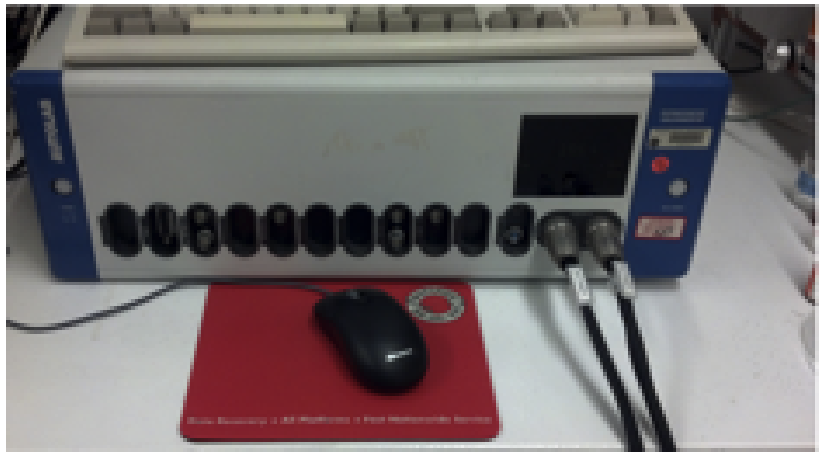

\section{Sterilizable WINCS Unit}

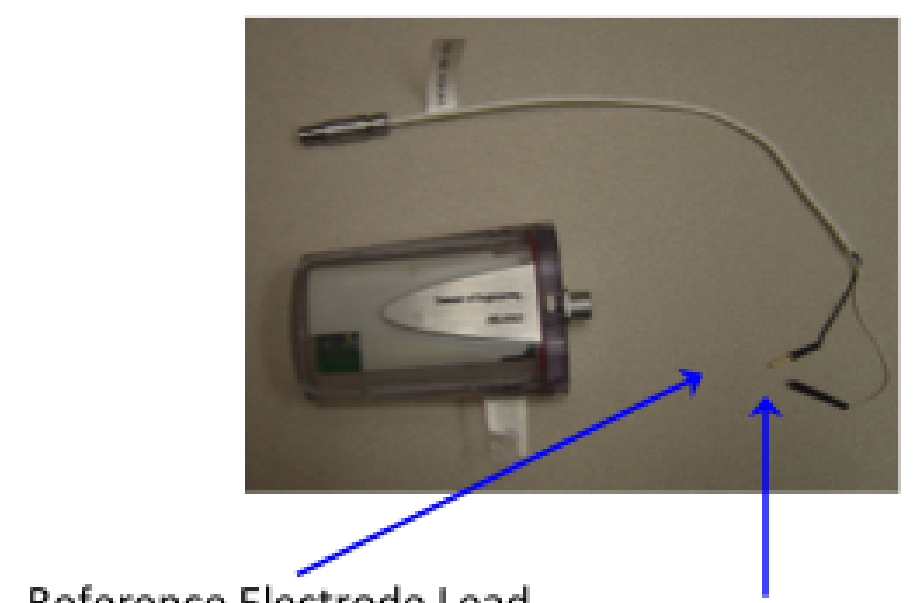

Reference Electrode Lead

Working Electrode Lead 


\section{Experimental Setup}

Custom-Designed Flow Cell

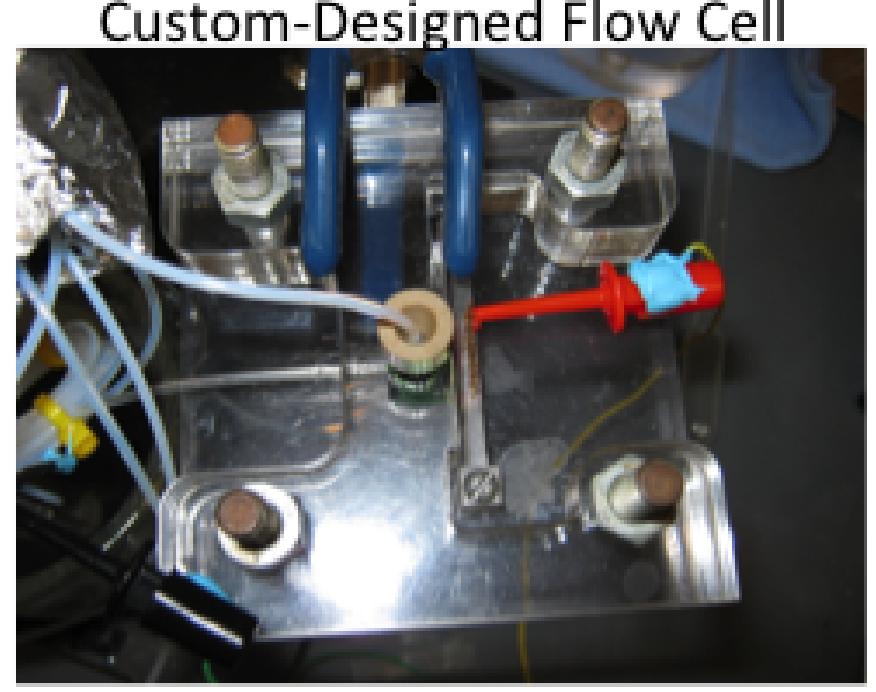

Cross-section:

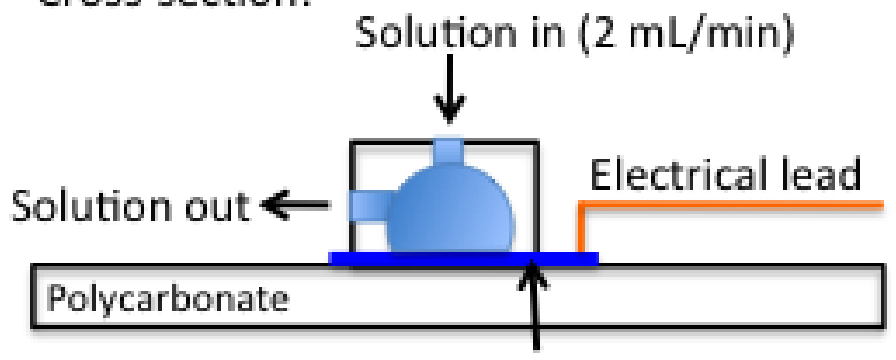

Sample

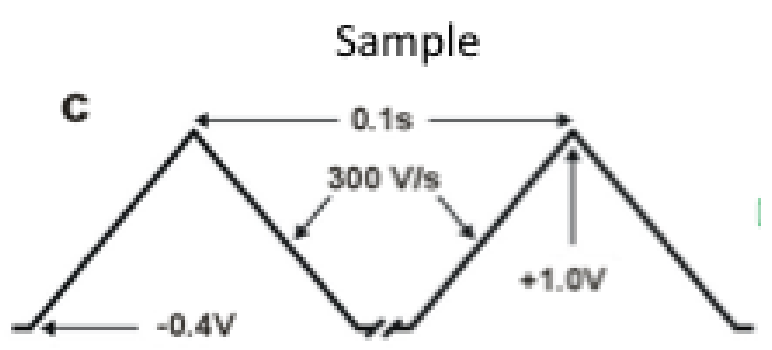

WINCSware User Interface

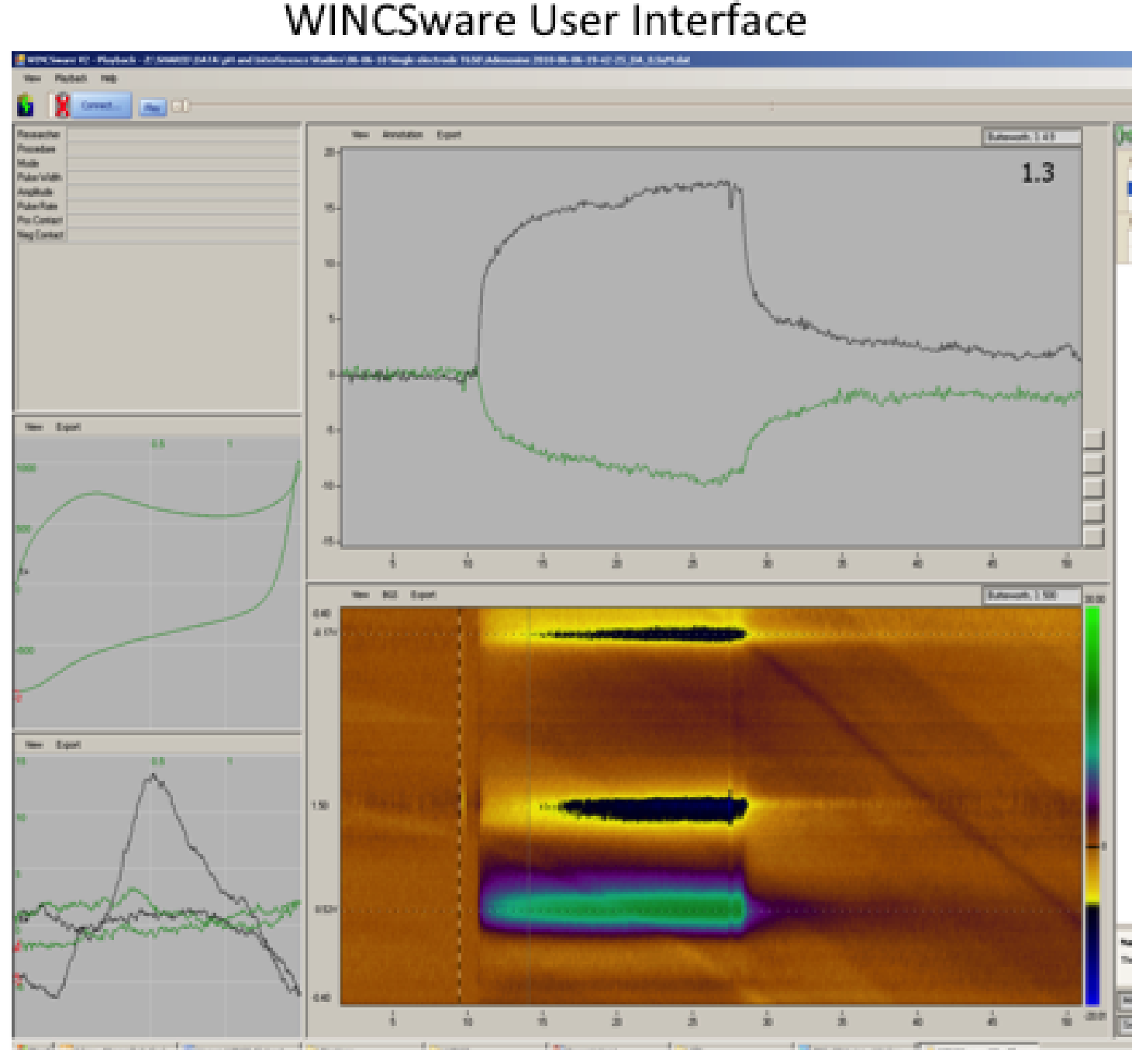

WINCSware allows viewing of the data in nearly real-time

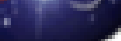




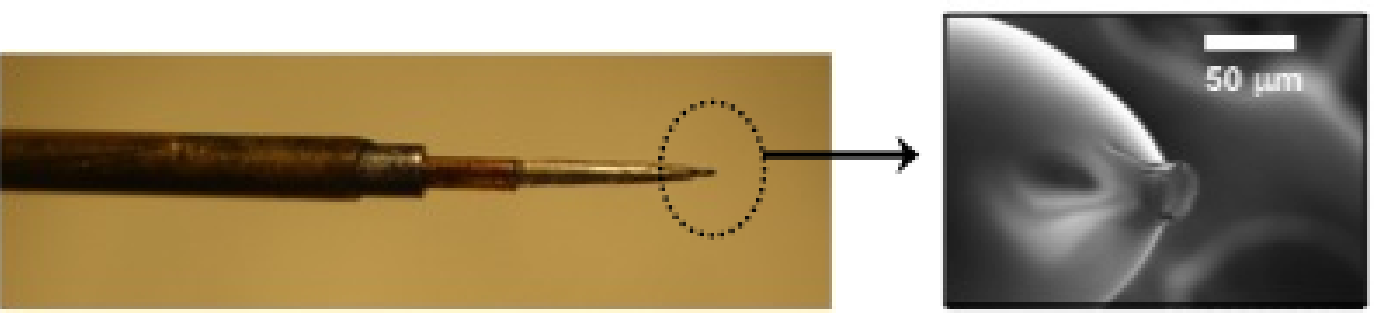

The WINCS carbon fiber electrode

(WINCStrode) is based on an approved

human extracellular tungsten

electrophysiology electrode that was

modified by the addition of a short section of

carbon-fiber to enable FSCV recordings.

\section{Dopamine Detection:}

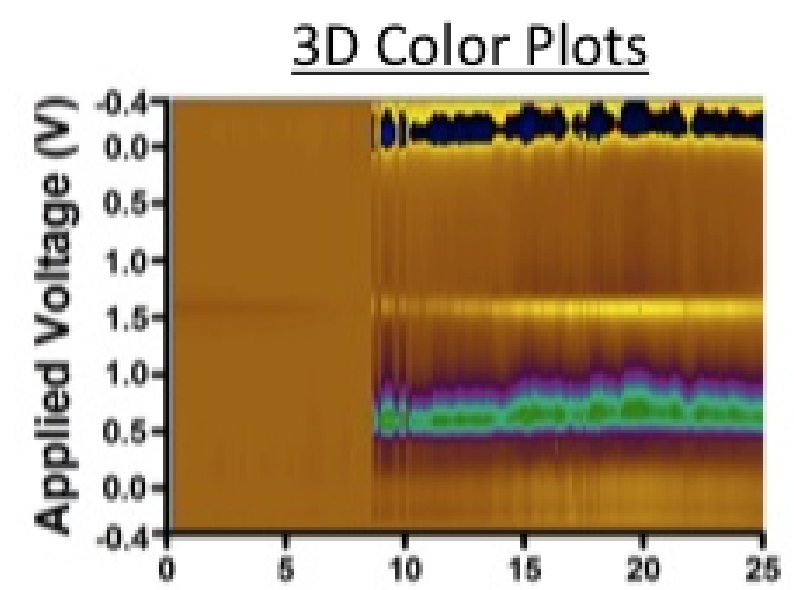

Background Subtracted

Cyclic Voltammogram

\section{Calibration Curve}
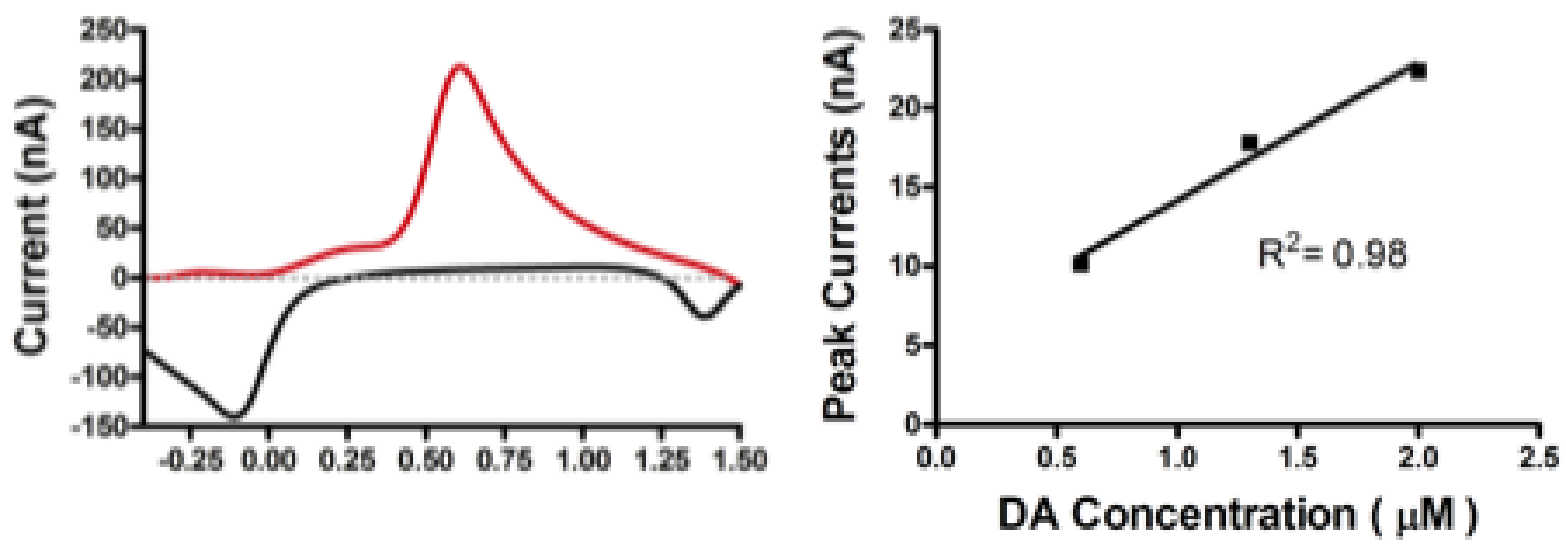
Scanning Electron Microscopy (SEM) Data:
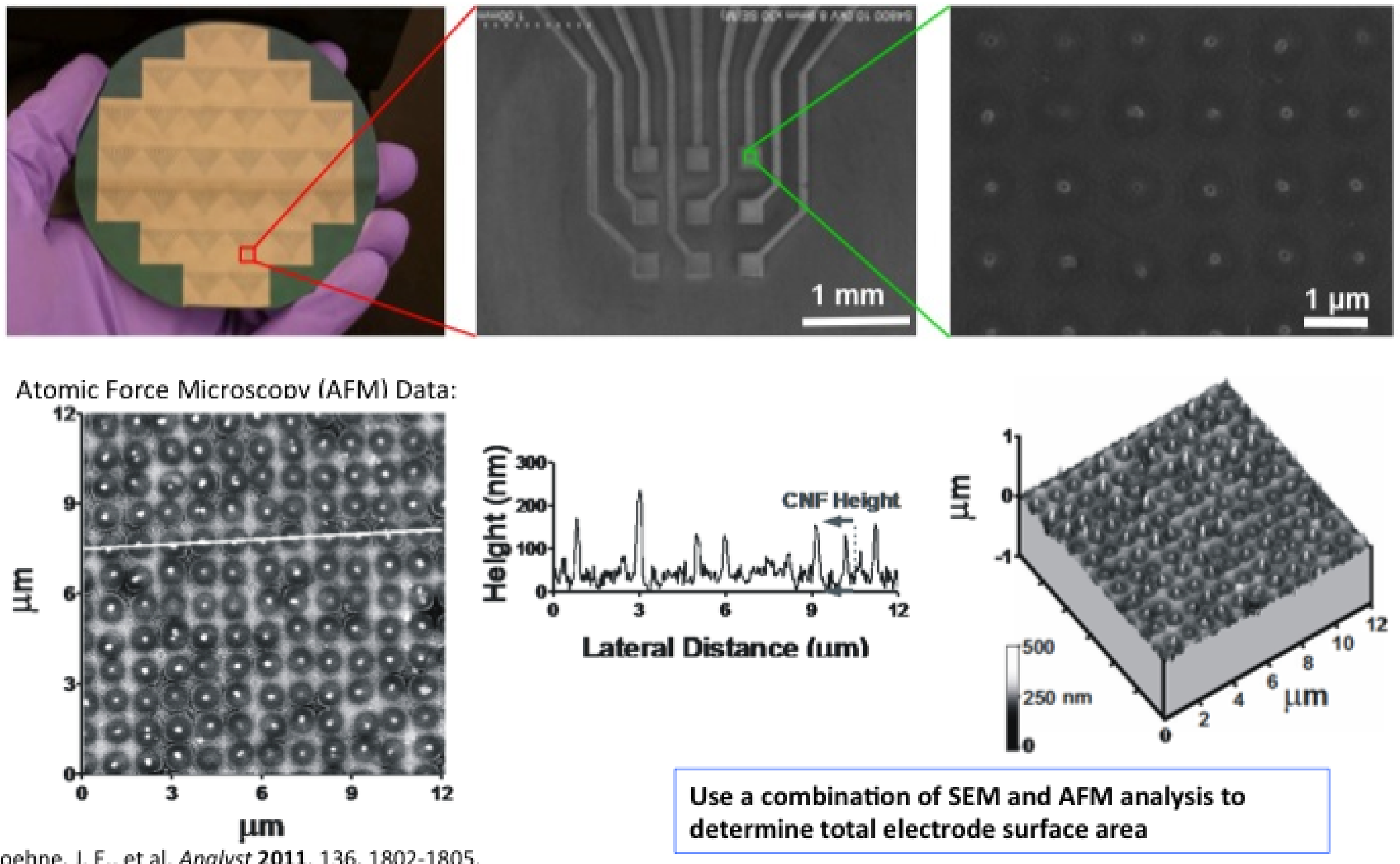

Use a combination of SEM and AFM analysis to

determine total electrode surface area

Koehne, J. E., et al. Analyst 2011, 136, 1802-1805. 


\section{Multichannel Crosstalk}
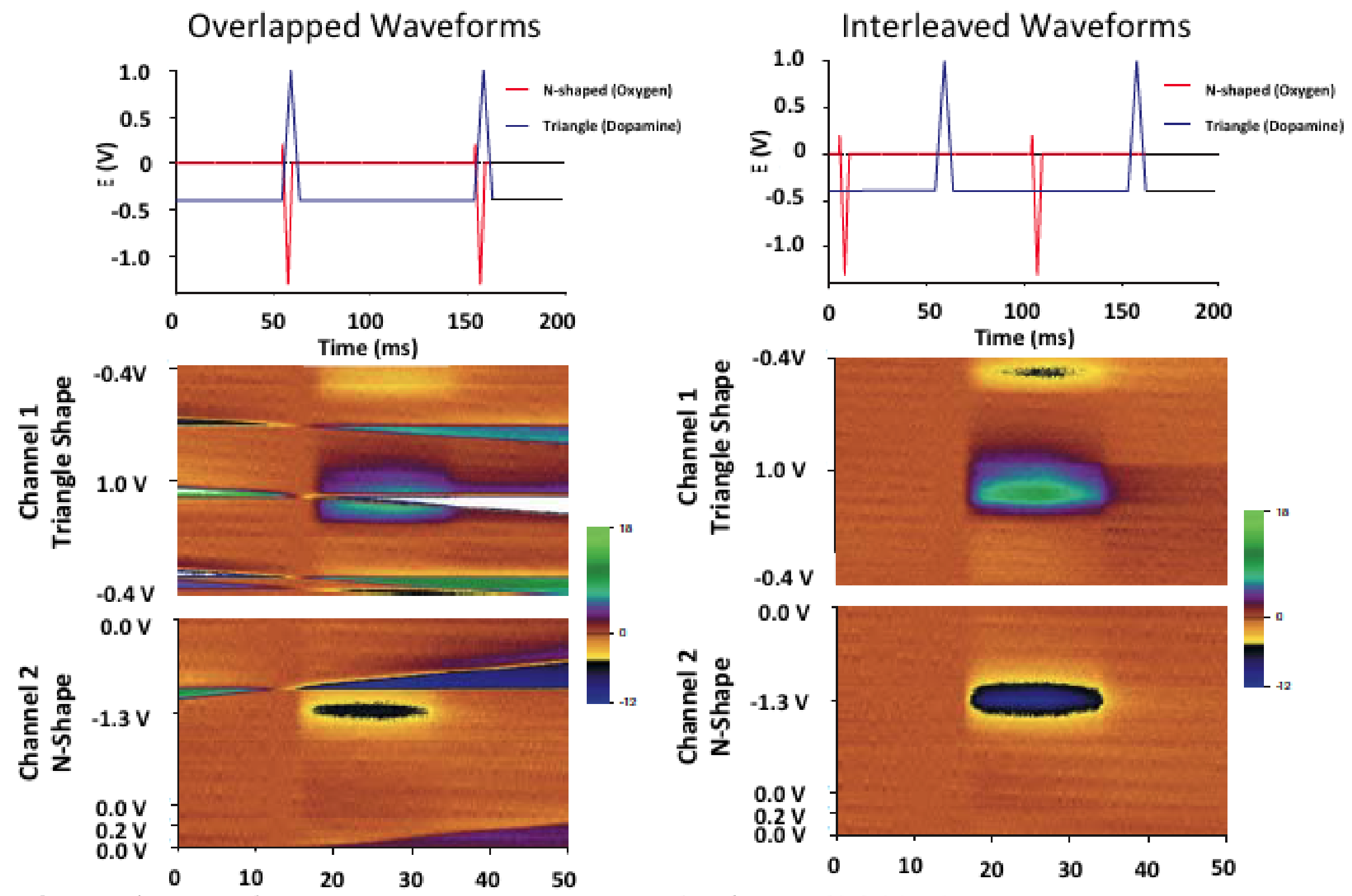

M. P. Marsh, J. E. Koehne, R. J. Andrews, M. Meyyappan, K. E. Bennet, K. H. Lee Biomed Eng Lett, 2012, 2,271-277. 
Penetrating multiplexed array

- Ability to spatially resolve
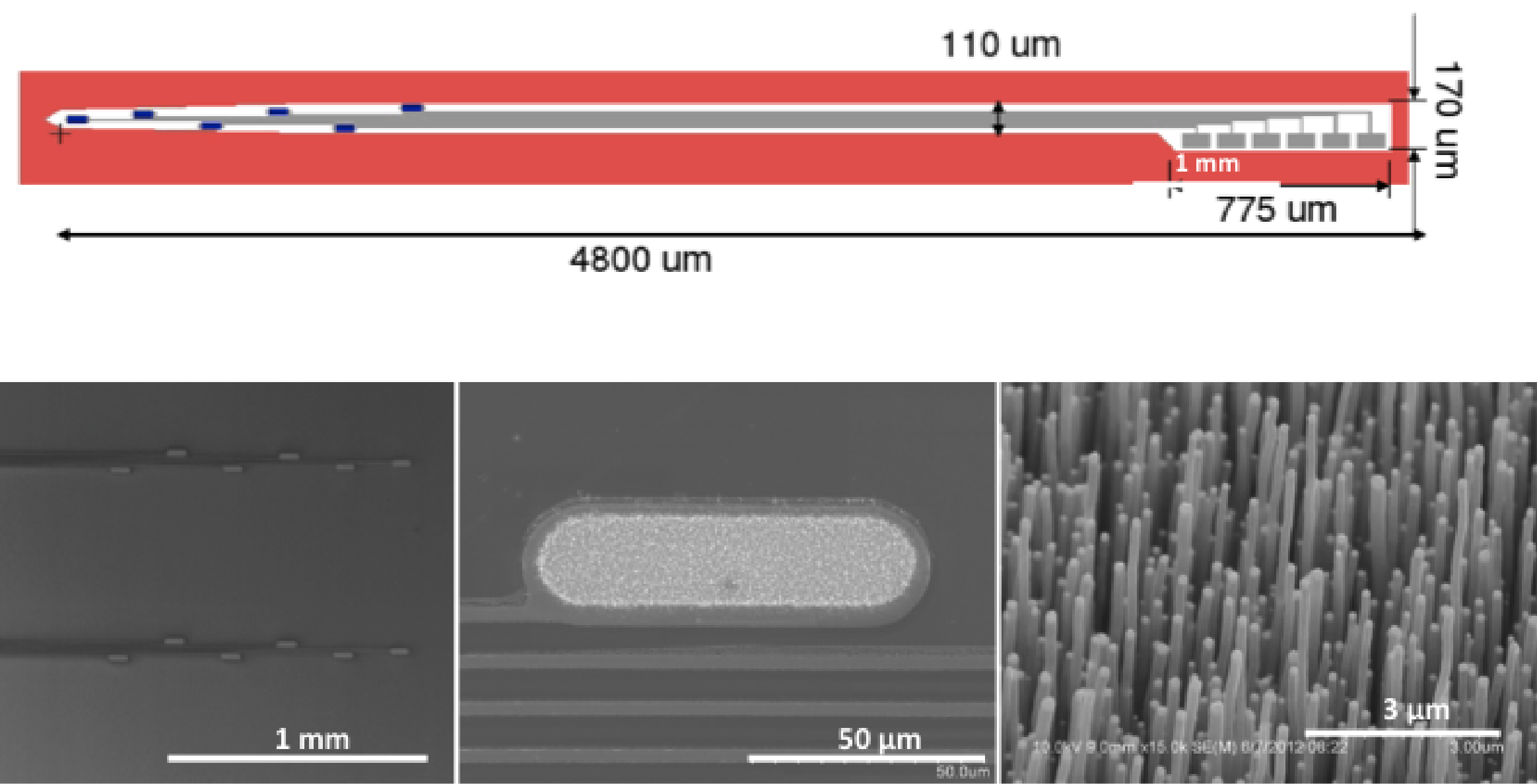
Needle Assembly

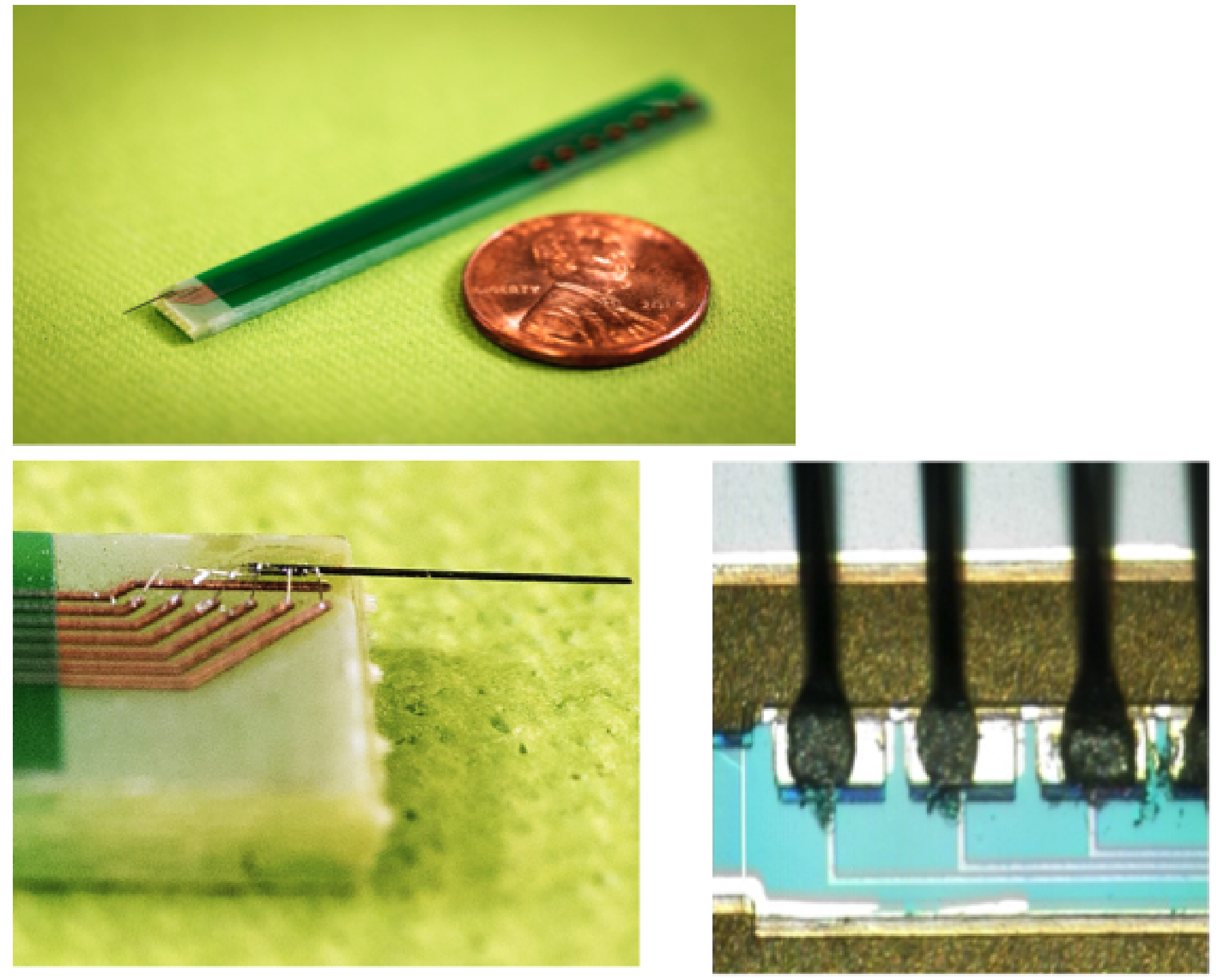




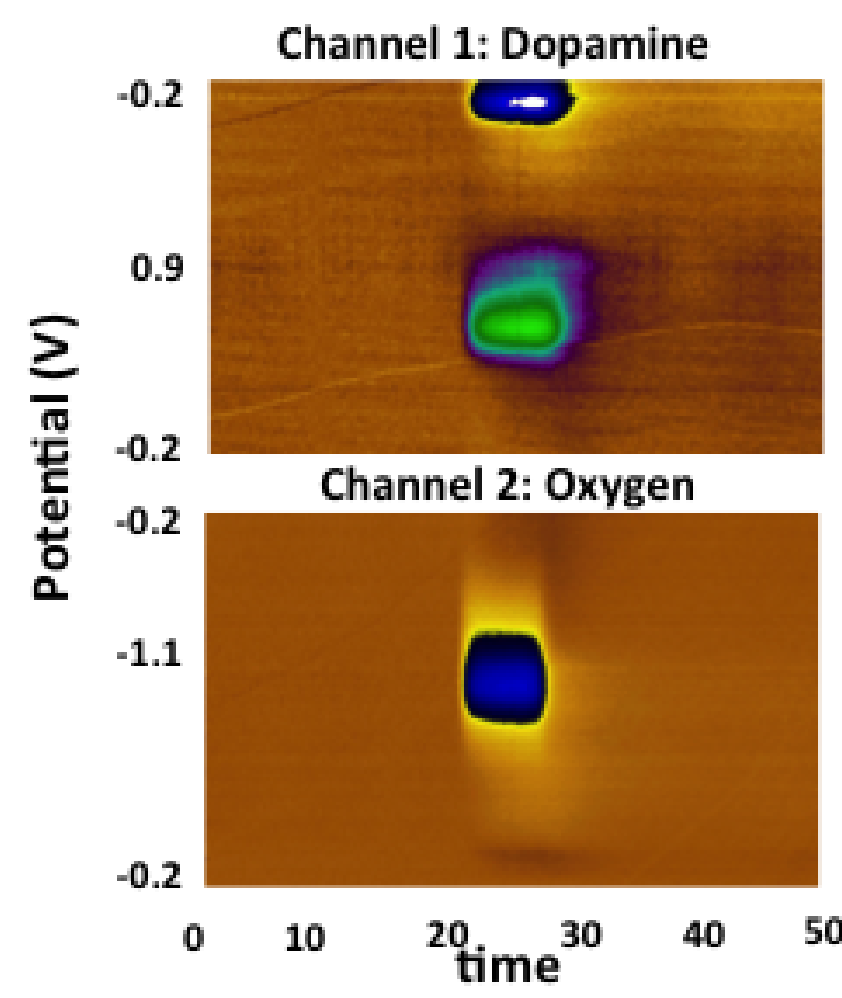

Background Subtracted Voltammograms

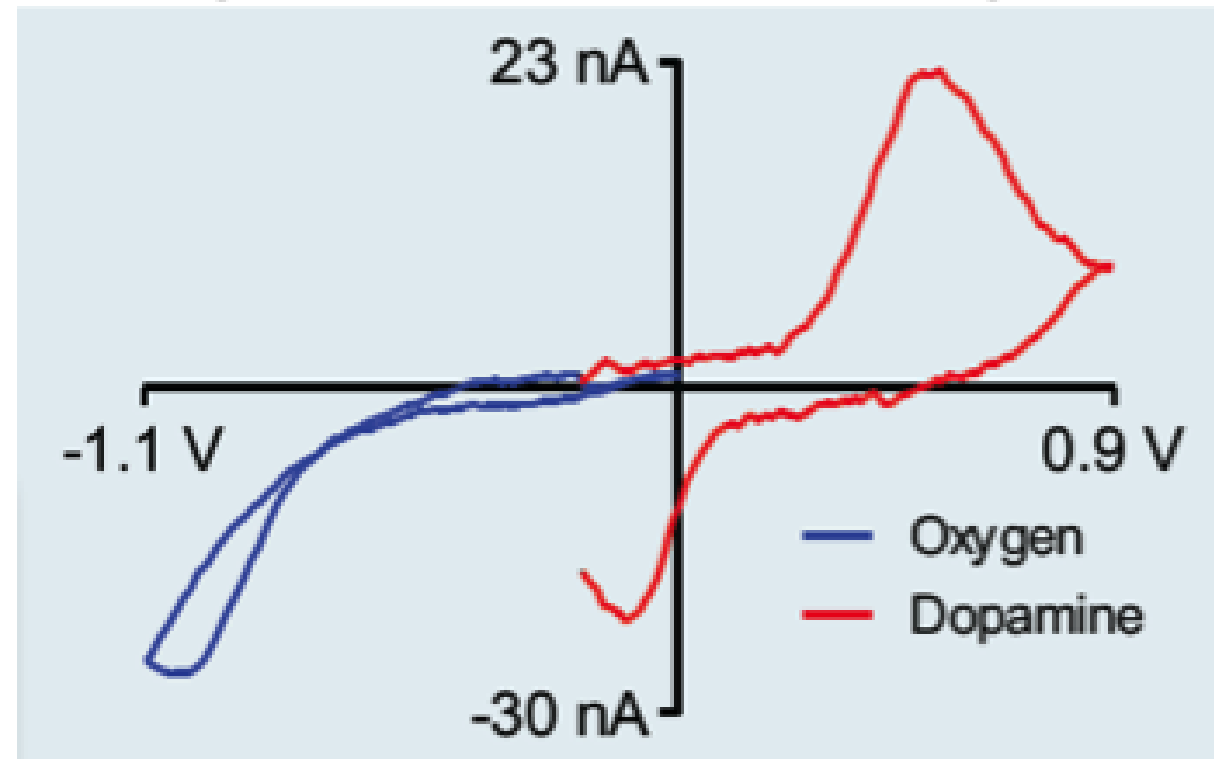

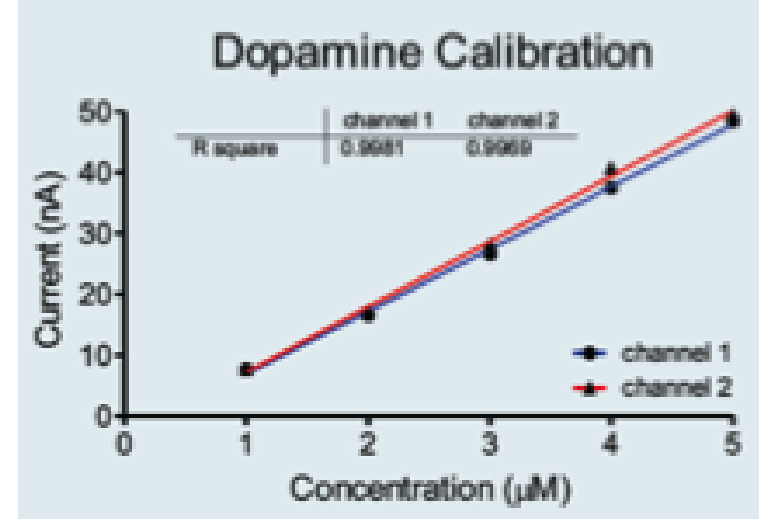

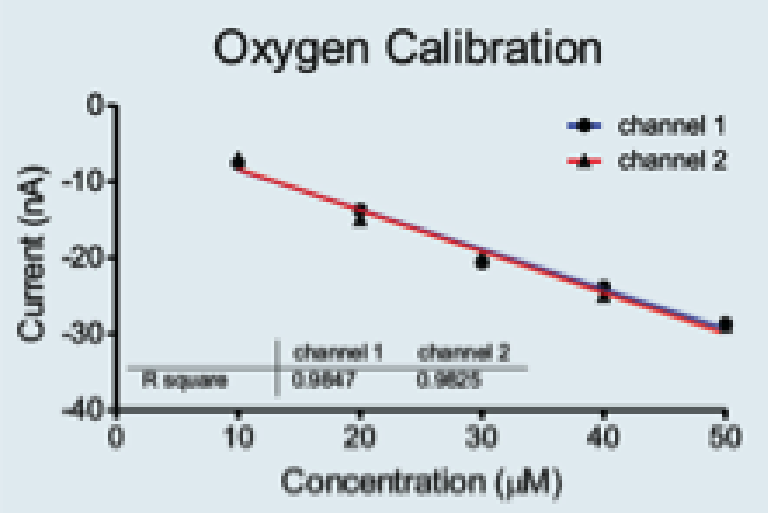

Increasing Oxygen with Constant

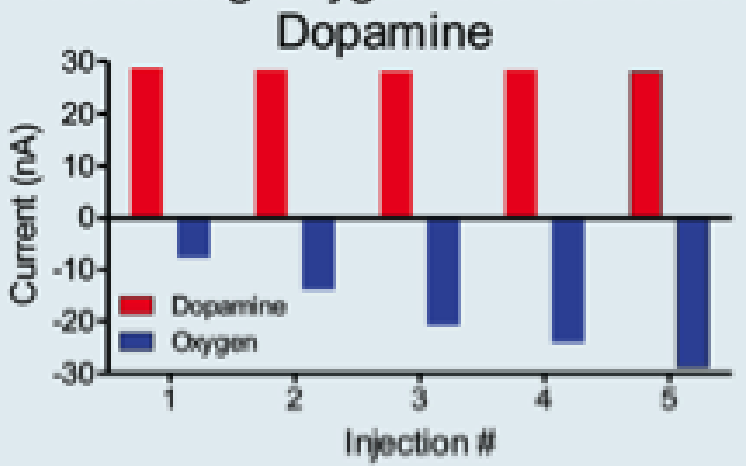




\section{Summary}

- Carbon nanofiber nanoelectrode arrays are easily fabricated using standard silicon processing

- CNF spacing defined by photolithography, e-beam lithography or top layer dielectric polishing time

- High surface area carbon nanofibers have been demonstrated as effective stimulation electrodes

- Conductive polymer coatings have allowed us to tune the electrical properties and biocompatability

- CNF sensors can distinguish between multiple electroactive analytes in a mixture using differential pulse voltammetry

- CNFs nanoelectrode arrays easily integrate with WINCS

- CNFs detect dopamine and oxygen with no channel crosstalk

- We have successfully fabricated a needle-like, implantable CNF electrode array for future in vivo investigations 


\section{Acknowledgements}

NASA Ames Research Center

- Emily Rand

- Adwoa Boakye

- Brandon Douglas

- Russell J. Andrews

- M. Meyyappan
- Mayo Clinic

- Department of Physiology and Bioengineering

- Michael Marsh

- Su-youne Chang

- Inyong Kim

- Kendall H. Lee

- Department of Engineering

- Christopher J. Kimble

- Kevin E. Bennet

\section{Funding}

NASA Ames Research Center

NIH (R01 Ns75013)

Presidential Early Career Award for Scientists and Engineers (NASA) 


\section{NASA \\ Educational Programs}

- NASA Internship Programs

http://intern.nasa.gov/

Fall, Spring and Summer Sessions

- NASA Fellowships

http://intern.nasa.gov/

http://www.nasa.gov/offices/oct/early_stage_innovation/grants NSTRF.html

Jessica.E.Koehne@nasa.gov 